\title{
DISPLACEMENT-BASED SEISMIC ASSESSMENT OF EXISTING REINFORCED CONCRETE BUILDINGS
}

\author{
M J N Priestley ${ }^{1}$
}

\begin{abstract}
This paper was presented as one of the keynote addresses at the Pacific Conference on Earthquake Engineering,
\end{abstract} PCEE 95, Melbourne, November 1995

\begin{abstract}
SUMMARY
Seismic assessment of existing reinforced concrete frame and shear wall buildings is discussed. Building on an earlier preliminary assessment procedure incorporating aspects of capacity design into a systems approach for assessment, suggestions are made towards a displacement-based, rather than forced-based approach to determining available capacity. Based on results from recent experimental programs, procedures are proposed for assessing member strength including column and beam-column joint shear strength, that result in less conservative estimates of performance than would result from application of existing code rules.
\end{abstract}

\section{INTRODUCTION}

The deficiency in expected seismic performance of existing unreinforced masonry buildings has long been recognized, with cities such as Los Angeles [1] and Wellington [2] requiring owners to strengthen or demolish deficient structures within a given time frame. Typically these buildings were designed before the advent of the first seismic design codes in the early 1930's. More recently, a second class of earthquake risk buildings (ERBs) has been identified $Ð$ reinforced concrete buildings designed between 1930 and about 1975, when design codes were implemented containing seismic provisions more or less equivalent to those currently in practice. Although steel and timber buildings should not be considered free of risk, they will not be considered herein. However, many of the principles discussed will be directly applicable to masonry buildings.

With the category of ERB considered in this paper, deficiency of seismic performance is generally a consequence of lack of ductility rather than inadequate lateral strength. Seismic design coefficients in current codes generally imply dependable inelastic cyclic response to significant levels of ductility. In older buildings, the ductility deficit is a consequence of two major failings in the original design process - poor detailing of reinforcement, and the lack of a capacity design philosophy. Deficiencies in detailing typically relate to amount, distribution, and anchorage of transverse reinforcement, though deficiencies in longitudinal reinforcement also exist. Frequently, transverse reinforcement in potential plastic hinge regions of beams, columns or walls is widely spaced, and anchored with $90^{\circ}$ bends in the cover concrete. Spalling of compression concrete then leads to buckling of longitudinal reinforcement and collapse of the plastic hinge region. Shear reinforcement is also frequently inadequate, particularly in potential plastic hinge regions, where the strength of concrete shear-resisting mechanisms can be expected to reduce with increasing ductility, as inclined flexureshear cracks increase in width, and aggregate interlock becomes increasingly ineffective. Beam-column joints were generally not designed with internal transverse reinforcement to carry the high shear stresses associated with moment reversal across the joint, resulting in a high potential for joint shear failure.

As a consequence of the lack of capacity design considerations in the design process, there is no assurance that a suitable hierarchy of strength exists to proscribe non-ductile modes of failure, such as shear failure, or limited ductile deformation mechanisms such as soft-story sway mechanisms. Design to an allowable stress rather than a strength design philosophy, as was common before the late 1960's contributes to uncertainty of inelastic response.

Complete assessment of the expected seismic performance of these buildings is not simple. Current established procedures tend to be rather rudimentary, and of the 'walk-through' variety, where details are compared with a check list of possible deficiencies, and where calculations, if carried out at all, are of a simplistic nature, inadequate to determine the probable response [3-6]. On the other hand, the development of damage indices relating damage levels of specific classes of structures to seismic intensity based on experience in past earthquakes is being inappropriately used to determine seismic risk of individual buildings. It is clear that the application of a mean value from a data set with extremely wide scatter will provide little insight beyond indicating the need for more detailed structural calculations. Unfortunately, these risk analyses are being routinely used to guide retrofit decisions and strategies for specific buildings. 
In a recent paper [7] an attempt was made to provide a more meaningful 'systems' approach to the assessment of existing frame buildings. A two-level seismic assessment procedure was outlined intended to determine the risk, in terms of annual probability of exceedance, associated with both serviceability and ultimate limit states. Determination of the ultimate limit state involved an attempt to identify the most critical collapse mechanism, and calculation of its associated strength and ductility in system response terms. Strength and structural ductility were combined to provide an equivalent elastic response force level, which, by comparison with the design elastic response spectrum could be used to determine annual probability of exceedence corresponding to development of structural capacity. The basis for identifying the critical collapse mechanism was a modified form of capacity design, which permitted local element failure provided overall structural integrity was not jeopardized.

In this paper, the procedure developed in [7] is re-examined, with systems response quantified directly in terms of structural displacement, instead of equivalent elastic strength. Strengths and deformation capacity of different critical mechanisms, in particular those relating to column shear strength and beamcolumn joint capacity are redefined, and ductility capacity of soft-story mechanisms discussed in greater detail. The revisions to the earlier approach are, to a considerable extent, based on experience with seismic assessment of concrete bridges [8,9]. Suggestions relative to assessment of reinforced concrete buildings with structural wall bracing systems are also made.

\section{DISPLACEMENT-BASED SYSTEM ASSESSMENT}

In the earlier procedure [7], an equivalent elastic acceleration was determined for the structure, corresponding to ultimate capacity of the critical inelastic deformation mechanism. This was found from the lateral strength and the structure displacement ductility capacity. The method for relating this to the equivalent elastic acceleration response, $S_{a(e)}$, assumed that the latter could be found from the relationship

$$
S_{a(e)}=R \cdot S_{a(\text { mech })}
$$

where

$$
R=1+\left(\mu_{s}-1\right) T / 1.5 T_{0}<\mu_{s}
$$

and where $S_{a(m e c h)}$ is the acceleration coefficient for the structure corresponding to the mechanism strength, $\mu_{s}$ is the structural ductility capacity corresponding to the mechanism investigated, $T$ is the elastic period of the structure, and $T_{0}$ is the period corresponding to peak spectral response (see Figure 1a). Equations (1) and (2) imply that the 'equal displacement' approximation (i.e., $R=\mu_{s}$ ) of structural response applies for $T \geq 1.5 T_{0}$, and that the response changes linearly from the 'equal acceleration' approximation $(R=1)$ at $T=0$, through the 'equal energy' approximation $\left(R=\sqrt{2 \mu_{s}-1}\right)$ at about $T=0.7 T_{0}$, to the equal displacement approximation at $T \geq 1.5 T_{0}$

The weakness of the above approach is the assumption about the relationships between ductile and equivalent elastic response (equal-energy, equal-displacement, etc.), and the lack of consideration of hysteretic energy dissipation characteristics. It also places undue emphasis on strength. In ductile systems, failure occurs not when the strength is reached, but when the ductility capacity (i.e., the ultimate displacement) is reached. It thus makes more sense to directly compare demand and capacity in terms of displacements. Even when the response is purely elastic, it is of equal validity to compare response in terms of displacement rather than acceleration terms.

Response can be considered directly in terms of displacement, using the substitute-structure approach of Shibata and Sozen [10]. In this, the structural period $T$ is not related to the initial elastic stiffness $k_{i}$, but to the effective stiffness $k_{\text {eff }}$ at maximum displacement, as shown in Figure 2a. Thus

$$
T=2 \pi \sqrt{M / K_{\text {eff }}}
$$

Maximum displacement demand corresponding to the design or assessment requirement, is found from a set of displacement response spectra, for different levels of equivalent viscous damping, as shown, for example in Figure 1b. The level of damping assumed depends on the structural ductility demand $\mu_{s}$,

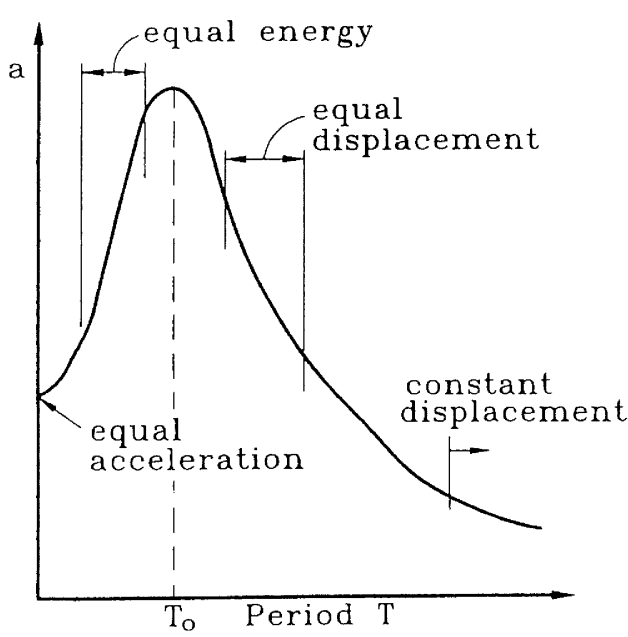

(a) Acceleration spectrum

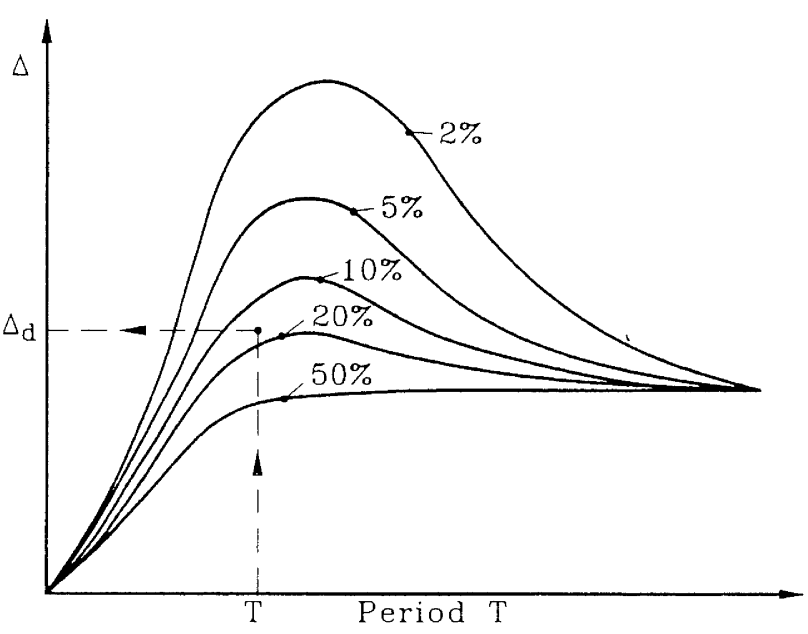

(b) Displacement spectra

FIGURE 1 Design Spectra for Assessment 


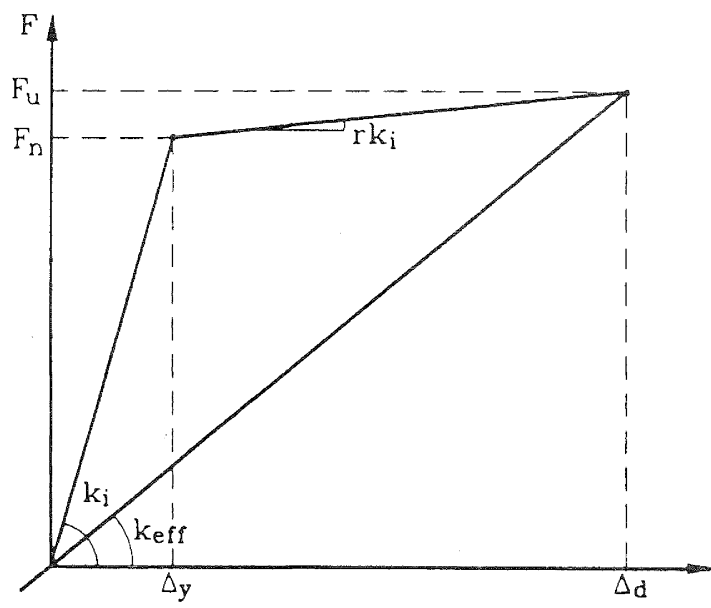

(a) Effective stiffness

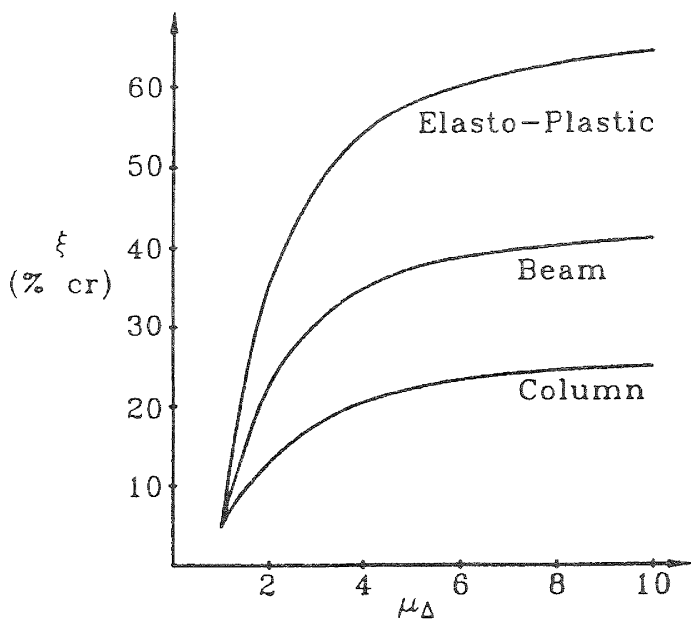

(b) Equivalent viscous damping

FIGURE. 2 Elements of Displacement-Based Assessment

and the predominant form of plastic hinging developed. As shown in Figure $2 b$, the energy dissipated in beam plastic hinges is typically larger than in column plastic hinges, and this should be recognized in the estimation of equivalent viscous damping.

Thus seismic response is characterized by an equivalent elastic stiffness and damping corresponding to maximum response, rather than initial values, based on $k_{i}$ and $5 \%$ damping, as typically used in force-based design or assessment.

With equivalent period and damping calculated, the required displacement $\Delta_{d}$ is read from the displacement spectra (Figure 1b), and compared with the ultimate displacement capacity $\Delta_{u}$. Seismic risk associated with achieving the ultimate displacement of the structure is then assessed from a relationship between the ratio $\Delta_{u} / \Delta_{d}$ and annual probability of exceedence, shown conceptually in Figure 3, where a value of $\Delta_{u} / \Delta_{d}=1$ corresponds to an annual probability of exceedence of 0.002 , or a return period of about 500 years - a common value used for design of new structures. The acceptable minimum level for $\Delta_{u} / \Delta_{d}$ is thus related to seismic risk, and is discussed later in this paper.

The approach outlined above has the advantage of directly considering displacements, which can be related to strain-based

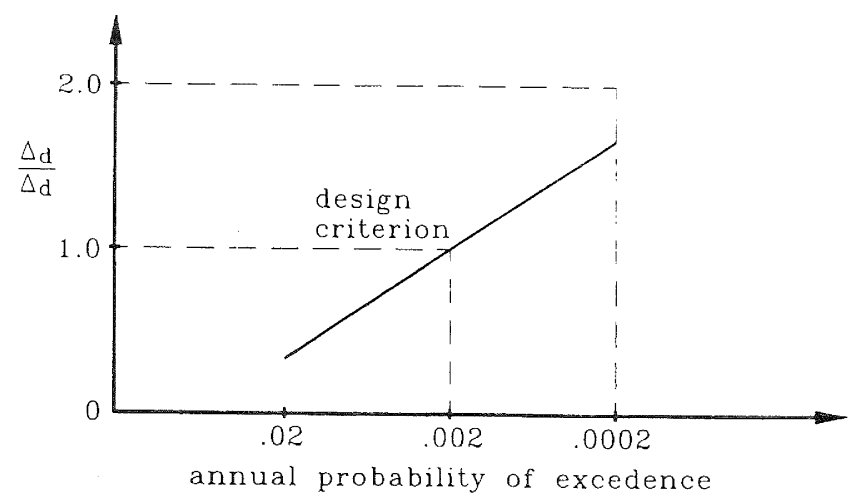

FIGURE 3 Relationship Between Annual Probability of Exceedence and Displacement Ratio limit states. These are clearly more fundamental to damage than force-based limit states, even when serviceability, rather than ultimate conditions are considered. For example, it is currently common to define the serviceability limit state as corresponding to the limit of 'elastic' response, or to a structure displacement ductility demand of $\mu_{s}=1$ (these are not necessarily the same), despite the fact that the onset of damage at a level requiring repair, and thus influencing serviceability, as evidenced by unacceptably wide crack widths and/or concrete spalling, will rarely correspond to such a low level of response, depending critically on such aspects as axial load level in members, and type of inelastic deformation mechanism achieved. A serviceability limit corresponding to $\mu_{s}=1$, while generally (though not exclusively) conservative, provides a very uneven level of protection against damage. Use of a displacement-based assessment procedure, where the structural displacement corresponding to development of serviceability limit strains (say peak concrete compression strain $=0.005$, or peak reinforcement tensile strain $=0.01$ ) enables a consistent level of assessment to be achieved.

The procedure resommended above requires generation of assessment displacement spectra representing acceptable performance. In theory, these can be simply generated from acceleration spectra using the normal relationships between peak acceleration and displacement of elastic oscillators. However, it should be recognized that design acceleration spectra are often unrealistically high in the long period range. This is typically a consequence of a deliberate decision to enforce minimum strength requirements for long period structures, rather than a reflection of expected seismic response. Determination of spectral displacements from design acceleration spectra thus typically result in displacements which continue to increase with period even at very large values of $T$, though it is known that the characteristics shown in Figure $1 b$ are more realistic. Here, spectral displacements reach a maximum, and then decrease again at large periods, eventually reaching a stable value equal to the peak ground displacement, regardless of ductility level or period. The implication is that the equal displacement approximation can be expected to be excessively conservative in the long period range. The influence of this conservatism in existing spectra will be greater in a substitute structure analysis, based on effective period at maximum response, than in an 
initial-stiffness force based analysis. Consequently, for seismic assessment, it is important to use a set of displacement spectra that is as realistic as possible.

The characteristics of 'real' displacement response spectra are shown, by example, in the Sylmar record from the 1994 Northridge earthquake, recorded close to the epicenter, which displayed a peak ground acceleration of $0.85 \mathrm{~g}$. As shown in Figure 4, a peak spectral displacement of about $750 \mathrm{~mm}$ occurred at about $T=2.5 \mathrm{secs}$, for $5 \%$ damping. However, for equivalent viscous damping of about $20 \%$, which is typical of stable hysteretic response of systems with column hinges, the response is essentially flat at about $450 \mathrm{~mm}$ for $T \geq 2$ secs. The implication is that satisfactory response of longer period structures could be assured under this extreme record, which represents ground shaking about twice the maximum design event for New Zealand, provided a displacement capacity of $\Delta_{u}>450 \mathrm{~mm}$ was available, regardless of available strength.

For regions of only low to moderate seismicity, such as much of Australia, this approach may have increased significance in assessment, since the M5 to M6 earthquakes, which could be considered to represent extreme events, may have high peak spectral response accelerations, but rather low peak spectral displacements. It would thus seem that flexible structures reasonably designed for gravity loads are unlikely to be at significant risk of collapse in such cases.

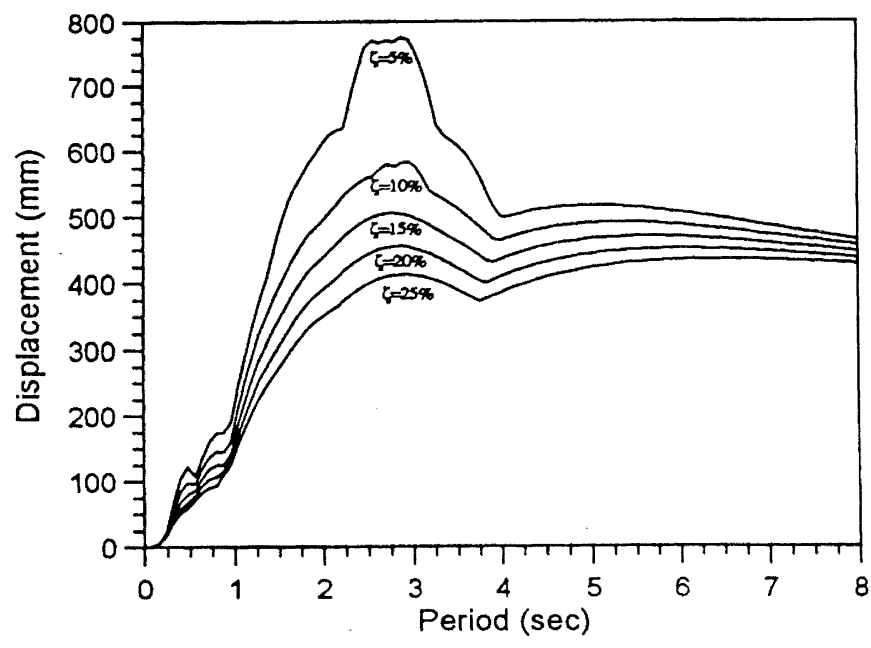

FIGURE 4 Displacement Spectra for 1994 Northridge Earthquake (Sylmar Records)

\section{MECHANISM CONSIDERATIONS}

A fundamental aspect of seismic assessment is the identification of the probable inelastic deformation mechanism. This requires comparison of flexural and shear strength of members, to determine whether flexural or shear failure is anticipated, and comparison of the relationship between strengths of beams and columns framing into joints, to determine whether beam-sway or column-sway mechanisms are likely to form. The problem of sway mechanism determination is discussed first.

In a full capacity design procedure, column moment capacities are required to have a substantial margin of strength over beam capacities framing into the same joint, to ensure the desired weak-beam/strong column performance develops, thus proscribing column-sway mechanisms. If column hinges are to be completely avoided, then the margin of strength must reflect the influence of higher mode response as well as potential beam flexural overstrength [11]. However, less conservative measures are appropriate if individual column hinging is permitted, provided that a full story column-sway mechanism does not develop. A column-sway mechanism involves the formation of plastic hinges at the top and bottom of all columns at one level of a frame, as shown, for example, in Fig. 5b. Thus formation of individual column hinges should not be seen as particularly serious, since some flexural ductility capacity of the column hinges will exist, and only very minor plastic rotations can develop in the column hinges until a full story mechanism develops.

As discussed in [7], the potential for developing a column-sway mechanism can be determined from the value of a sway potential index, $S_{p}$. This is defined by comparing the flexural capacities of beams and columns at all joints at the level immediately above and below the suspect line of columns. For a line of $j$ columns between levels $n$ and $n+1$ of a frame

$$
S_{p}=\frac{\sum_{i=1}^{j}\left(\Sigma M_{B n, i}\right)+\sum_{i=1}^{j}\left(\Sigma M_{B n+1, i}\right)}{\sum_{i=1}^{j}\left(\Sigma M_{C n, i}\right)+\sum_{i=1}^{j}\left(\Sigma M_{C n+1, i}\right)}
$$

where $\quad \Sigma M_{B m, i}=$ sum of beam moment capacities (left + right) at the joint centroid of joint $i$, level $n$

$\Sigma M_{C n, i}=$ sum of column moment capacities (upper and lower) at the joint centroid of joint $i$, level $n$

If $S_{p}>1$, a column-sway mode is expected. However, since the consequences of a soft-story mode is a greatly reduced structural plastic displacement capacity, as compared to a beamsway mode as discussed subsequently, a change from $S_{p}=0.98$ to $S_{p}=1.02$ would imply great variation in capacity. To avoid uncertainties in material properties and small errors in calculations unduly influencing the predicted sway mode, and to provide some recognition of higher mode effects, it is recommended that a column sway mechanism be assumed to develop when $S_{p}>0.85$.

Having determined the expected sway mechanism, and its inelastic deformation capacity (as subsequently discussed) in terms of story drift, the structural displacement at the center of seismic force may be found. This requires investigation of the shape of the plastic deformation profile, as shown in Figure 6. Ideally, this should be found from an inelastic frame lateral response analysis, incorporating all potential member nonlinearities. This can be achieved using special purpose 'push analysis' programs [e.g. 12], or by use of dynamic inelastic time history analyses [e.g. 13] where the lateral force vector is gradually increased in magnitude sufficiently slowly to ensure that dynamic modes of the structure are not excited. However, this assumes a knowledge of the shape of the lateral force vector, which will typically be assumed to be an inverted triangle, and which may be a reasonable approximation of the elastic displacement profile. If an inelastic deformation mode develops with a displaced shape markedly different from the assumed inverted triangular shape, as would be the case for a soft story column sway mode, the vertical distribution of forces in the lateral force vector would gradually deviate increasingly from the inverted triangle shape. To warrant the sophistication of an inelastic static mechanism, or push analysis, it would seem that it would be necessary to be able to modify the shape of the 


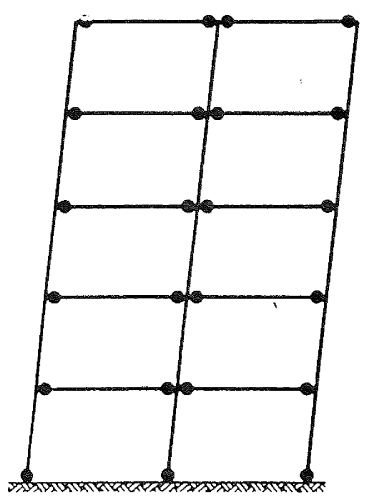

(a) Beam sway

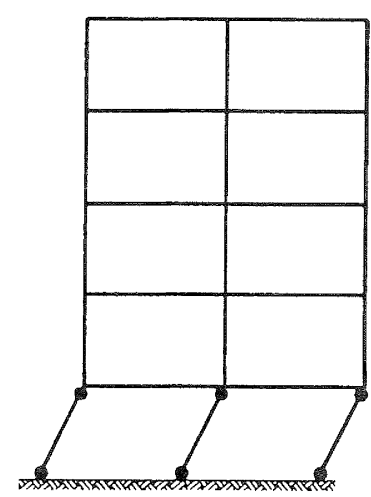

(b) Column-sway (soft story)

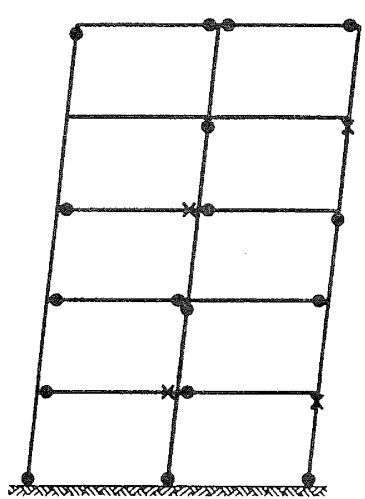

(c) Mixed mode

\section{FIGURE 5 Plastic Collapse Mechanisms}

lateral force vector, as plastic displacements increase. Although not conceptually difficult to implement in a push analysis, it is not currently available in any computer program, to the writer's knowledge.

The considerations discussed above are, however, relatively straightforward to implement in a hand analysis, though the degree of precision must be recognized to be rather coarse. Since our ability to determine realistic characteristics for design (or assessment) seismicity is of considerably greater coarseness, this should not be seen to invalidate this simple process.

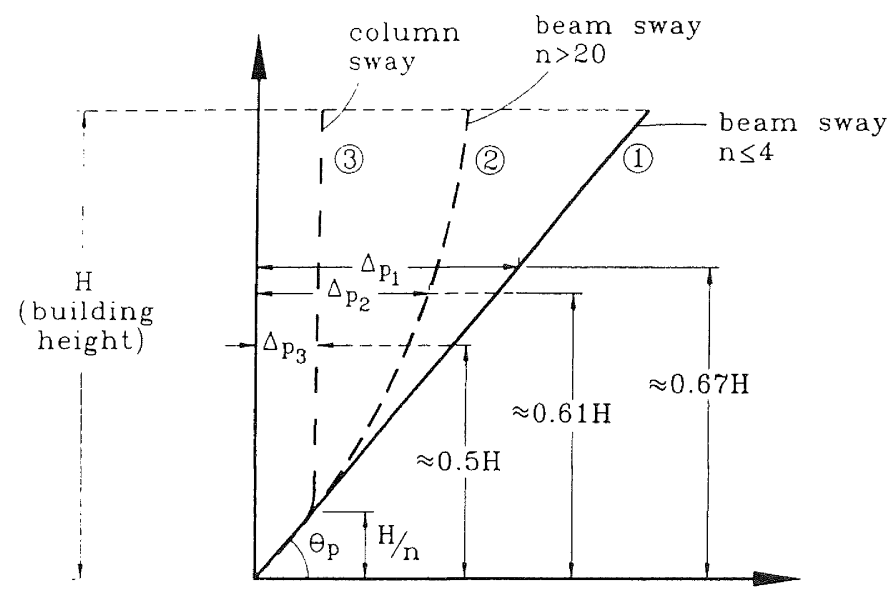

FIGURE 6 Plastic Displacement Profile for Frames

Consider the plastic displacement profiles of Figure 6. Three cases are considered, all with the same maximum plastic drift $\theta_{p}$, assumed to develop in the lowest story. The linear profile (1) corresponds to a beam sway mechanism in a low rise frame (say $n \leq 4$ ). For much taller frames (say $n>20$ ) dynamic inelastic analyses indicate that at peak response, the plastic displacement profile is nonlinear, with larger plastic drifts occurring in the lower floors. Paulay and Priestley [11] recommend a peak plastic drift equal to about twice the average over the building height, though there is some evidence that this may be excessive when hysteretic characteristics are used that are more representative of reinforced concrete behavior than the elasto-plastic analyses used as a basis for those recommendations.
Profile (2) shows the expected shape, assumed to be parabolic If a column sway mechanism develops in the lowest floor, the plastic displacement shape is represented by profile (3). Based on these shapes, the plastic displacement of the center of seismic force can be estimated. First, however, it must be recognized that the center of seismic force itself depends on the displaced shape. If an inverted triangle shape is a reasonable approximation of the elastic displacement response, then, initially the effective height of the single degree of freedom representation of the structure is approximately

$$
h_{\text {eff }}=0.67 H
$$

This is also the effective height for the plastic displacement profile (1) of the short frame, but profiles (2) and (3) have shapes with lower centroids ( $h \approx 0.61 H, h \approx 0.5 H$ respectively). Thus as inelastic displacement increases the center of seismic force gradually decreases from $h_{\text {eff }}=0.67 \mathrm{H}$ at $\mu_{s}=1$ to $h_{\text {eff }}=0.61 \mathrm{H}$ (or $0.5 \mathrm{H}$ ) at very large values of $\mu_{s}$.

For the beam sway mechanisms, the effect is not particularly significant, and it is suggested that, for regular structures, both elastic and plastic displacements be determined at an effective height of $0.64 \mathrm{H}$. It is also suggested that the displaced plastic shape be considered to vary linearly from profile (1) to profile (2) as $n$ increases from 4 to 20 . The plastic displacement at $0.64 H$ can thus be shown to be

$$
\begin{aligned}
n \leq 4 \Delta_{p} & =0.64 \theta_{p} H \\
\text { for } n \geq 20 \Delta_{p} & =0.44 \theta_{p} H \\
4<n 20 \Delta_{p} & =(0.64-0.0125(n-4)) \theta_{p} H
\end{aligned}
$$

For the column sway mechanism (profile (3)), $h_{\text {eff }}$ should reflect the ductility level. Thus, approximately

$$
h_{e f f}=\left[0.64-0.14\left(\mu_{s}-1\right) / \mu_{s}\right]
$$

The plastic displacement $\Delta_{p}$ is given, for a structure of $n$ equal story heights $h_{s}$, as

$$
\Delta_{p}=\theta_{p} h_{s}
$$

i.e.,

$$
\Delta_{p}=\theta_{p} H / n
$$

Calculating the structural yield displacement $\Delta_{y}$ at the effective height $h_{\text {eff }}$, the ultimate displacement capacity is given by 


$$
\Delta_{u}=\Delta_{y}+\Delta_{p}
$$

and the displacement ductility by

$$
\mu_{s}=\Delta_{u} / \Delta_{y}
$$

In calculating the yield displacement, it is essential that member stiffness include the influence of cracking, and that foundation compliance effects be considered. Ideally, member stiffness should be based on moment-curvature analyses, at conditions corresponding to first yield, taking into account the influence of axial load and longitudinal reinforcement ratios. Failing this, simplifying recommendations, such as those in [11] can be adopted with reasonable accuracy.

The equivalent viscous damping and effective stiffness can thus be calculated as described in reference to Figure 2, and the displacement-based assessment procedure carried out as described above.

\section{MEMBER STRENGTH AND DEFORMATION CAPACITY}

The approach outlined so far has assumed a knowledge of member strength and deformation so that story shear force and drift capacity can be calculated. Some discussion of these points is warranted.

The basis of assessment should be to obtain a 'best estimate' of performance. Hence, it is inappropriate to use design values for material strength, which will generally be specified minima strength values, or at best, lower 5 percentile values.

Reinforcement: If mill certificates are available, use the average for the appropriate bar size. Otherwise, adopt a value of $f_{y a}=1.1 f_{y}$ as the assessment yield strength, where $f_{y}$ is the nominal yield strength (e.g., $275 \mathrm{MPa}$ or $414 \mathrm{MPa}$ ).

Concrete: There is likely to have been considerable strength increase with age since construction. Also, 28 day strength "as built" is likely to have significantly exceeded the nominal value as a result of conservative mix design. Since shear strength will often be of critical importance in seismic assessment, it is important to have as realistic as possible an estimate of concrete strength. The difference between using actual $\left(f_{c a}^{\prime}\right)$ and specified $\left(f_{c}^{\prime}\right)$ concrete strengths will not infrequently change the predicted failure mode from ductile flexure to brittle shear. Recent tests on concrete in 30 year old bridges in California have consistently resulted in compression strengths approximately twice nominal strength. Wherever possible, cores should be taken to assess typical strengths, or at least impact hammer measurements used and correlated with a few reference cores to determine $f_{c a}^{\prime}$. Failing this, a strength of $f_{c a}=1.5 f_{c}^{\prime}$ could be conservatively adopted, where $f_{c}^{\prime}$ is the nominal design value, unless visual inspection indicates poor quality or decayed concrete. In such cases, testing of cores should be considered mandatory.

\section{Beam Hinge Flexural Capacity}

Beam flexural strength should be assessed using an ultimate compression strain of 0.005 , since this represents a lower limit on recorded crushing strains of plastic hinges forming against supporting members (in this case, columns) for normal strength concrete $\left(f_{c a}^{\prime}<50 \mathrm{MPa}\right)$. However, if a moment-curvature analysis incorporating strain-hardening of reinforcement is used to assess flexural strength, positive moment capacity predicted at an extreme fiber compression strain of 0.005 will correspond to excessive tensile strains, when, as is normally the case, the area of top (compression) reinforcement exceeds that of the bottom (tension) reinforcement. For such cases, flexural strength should be assessed when peak tensile strain in reinforcement is about $\epsilon_{s}=0.02$.

The effective slab width contributing to beam negative moment capacity is primarily a function of ductility level and slab reinforcement details. As an approximation guide, the width may be taken as the lesser of $1 / 4$ of the beam span, or $1 / 2$ of the transverse beam span for a beam framing into an interior column, or $50 \%$ of this value for beams framing into an exterior column. These values may be conservatively low at high ductility levels. A more complete consideration of these effects is given in reference [11].

\section{Plastic Rotation Capacity}

The plastic rotation capacity of the beam plastic hinges defines the plastic story drift $\theta_{p}$ in a beam-sway mechanism. This will depend primarily on the detailing of the transverse reinforcement in the potential plastic hinge regions at the beam ends. In the earlier methodology [7] rather crude rules were presented relating structural ductility capacity $\mu_{s}$ to level of detailing provided, with values of $\mu_{s}=2$ corresponding to 'bad' detailing and $\mu_{s}=6$ corresponding to detailing conforming to requirements of current codes, such as NZS3101 [14] Interpolation was suggested for intermediate cases. In view of the variability of reinforcement detailing, and in relationships between story drift and structural displacement ductility, this is felt to be too coarse. Although the precision with which plastic drift capacity of existing structures can be predicted is still not high, some more specific guidance can be given. In particular, the emphasis in the displacement-based assessment procedure must be on a specific quantification of plastic hinge rotation $\theta_{p}$.

Figure 7 presents information relative to predicting $\theta_{p}$ for the beams of typical frames. Using techniques normally employed for assessment of bridge bents [9], the plastic rotation capacity can be expressed as

$$
\theta_{p}=\left(\phi_{u}-\phi_{y}\right) L_{p}
$$

where $\phi_{u}$ and $\phi_{y}$ are ultimate and yield curvatures, and $L_{p}$ is the equivalent plastic hinge length, given by

$$
L_{p}=0.08 L+0.022 f_{y a} d_{b \ell}
$$

The first term in Equation (10) represents the spread of plasticity due to member length, with $L$ being the distance from the critical section to the point of contraflexure. The second term represents strain penetration into the supporting member (i.e., the column), with $f_{y a}$ being the yield strength (MPa) of the beam longitudinal bars, of diameter $d_{b \ell}$. As shown in Figure $7 \mathrm{a}$, the distance between the critical section and the point of contraflexure will depend on relative flexural strength of positive moment and negative moment plastic hinges, and the relative importance of seismic and gravity moments. However, it is suggested that for negative moment plastic hinges, which will generally form against the column face, (point $\mathrm{A}$, Figure 7a) a length $L=0.5 L_{c}$, where $L_{c}=$ beam clear span, be assumed. This is a reasonable reflection of the fact that (i) negative moment capacity will exceed positive moment 


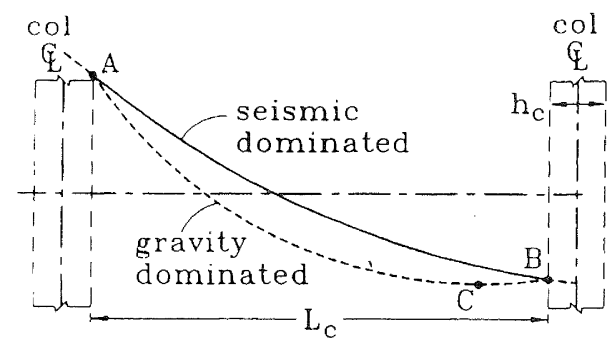

(a) Span elevation

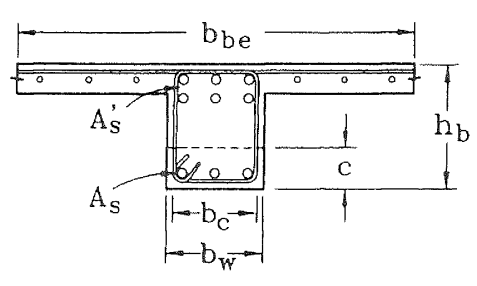

(b) Beam section

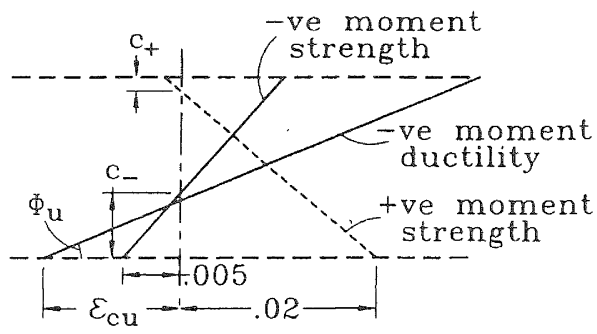

(c) Strain profiles

FIGURE 7 Considerations for Beam Plastic Hinges

capacity, and (ii) high shear stress levels in the plastic hinge region will tend to extend the effective plastic hinge length due to tension shift effects.

The positive moment hinge could form at the column face, (point B, Figure $7 \mathrm{a}$ ) or within the span (point $\mathrm{C}$ ), depending on the influence of gravity loads on the beam. However, the location, which is always hard to define due to uncertainty in the magnitude of gravity loads, and the plastic rotation capacity of the positive moment hinge are of little interest in assessment of plastic rotation because this will generally greatly exceed the rotational capacity of the negative-moment hinge. This is a consequence of (i) top reinforcement area $A_{s}^{\prime}$ (including slab contribution) exceeding bottom reinforcement area $A_{s}$, and effective compression zone width $b_{b e}$ for positive moments exceeding the web width $b_{u^{\prime}}$, appropriate for negative moments (see Figures. $7 \mathrm{~b}$ and $7 \mathrm{c}$ ). This results in a greatly reduced compression zone depth $c_{+}$for positive moments compared to that for negative moments, $c_{-}$, as illustrated in Figure $7 \mathrm{c}$. Since compatibility of the story deformed shape requires that the plastic rotations of all plastic hinges along a beam are essentially equal at any given stage of response, and since plastic hinge lengths for positive moment can be expected to exceed those for negative moment, it follows that the critical condition, corresponding to attaining the ultimate compression. strain $\epsilon_{c u}$ in a plastic hinge, will always be in a negative-moment hinge. It can readily be shown that the theoretically feasible condition of attaining ultimate tensile strain in the positive moment hinge is unrealistic at curvatures corresponding to the ultimate negative moment curvature.

Figure $7 \mathrm{c}$ shows strain conditions to be used for estimating flexural strength of positive and negative moment hinges, and ultimate conditions for the negative moment hinge. For 'unconfined' conditions, corresponding to

- $\quad$ only corner bars restrained against buckling by a bend of transverse reinforcement and

- hoop stirrup ends not bent back into the core and

- $\quad$ spacing of hoop or stirrup sets in the potential plastic hinge such that

$$
s \geq d / 2
$$

or

$$
s \geq 16 d_{b \ell},
$$

the ultimate concrete strain should be assumed to be 0.005 , thus corresponding to conditions at determination of flexural strength.
For 'fully confined' conditions, corresponding to details satisfying current codes:

- All beam bars in the lower layer (i.e., if more than one) of bottom reinforcement restrained against buckling by transverse reinforcement of diameter greater than $d_{b \ell} / 4$.

- All transverse reinforcement anchored by hooks bent back into the core by standard $135^{\circ}$ hooks or equivalent anchorages

- Spacing of hoop or stirrup sets not less than $s=d / 4$ nor $s=6 d_{b \ell}$,

the ultimate concrete strain may be assumed to be

$$
\epsilon_{c u}=0.004+\frac{1.4 \rho_{s} f_{y h} \epsilon_{s u}}{f_{c c}^{\prime}}
$$

where the volumetric ratio of transverse reinforcement $\rho_{s}$, may be approximated as

$$
\rho_{s}=1.5 A_{v} / b_{c} s
$$

where $A_{v}=$ total area of transverse reinforcement in a layer, at spacing $s$, and $b_{c}=$ width of beam core, measured from center to center of the peripheral transverse reinforcement in the web. In Equation (11) $f_{y h}$ is the yield strength of the transverse reinforcement, $\epsilon_{s u}$ is the strain in the transverse steel at maximum stress, and $f_{c c}^{\prime}$ is the compression strength of the confined concrete. For older designs, it is recommended that $\epsilon_{s u}=0.15$ and 0.10 for $f_{y}=275$ and $420 \mathrm{MPa}$ transverse reinforcements, respectively. In lieu of a more accurate analysis $[9,15] f_{c c}^{\prime}=1.5 f_{c u}^{\prime}$ may be assumed

For conditions intermediate between unconfined and fully confined, interpolation will be required.

An example of this approach is given in Figure 8, where moment-curvature curves for positive and negative moment bending of a typical beam section are shown. A bay length of $6 \mathrm{~m}$ is assumed, which, with a column size of $450 \mathrm{~mm}$ square gives an effective clear span of $5.55 \mathrm{~m}$. Top steel area including the contribution of slab reinforcement over a $3000 \mathrm{~mm}$ effective width is more than double the bottom steel area. Despite this high steel ratio, the strengths of the section in positive and negative bending are not greatly different at high curvatures, due to cover spalling and a deep compression zone depth for negative moments, and strain hardening for positive moments. At the limit curvature for unconfined negative bending $\left(\epsilon_{c}=0.005\right)$ the positive moment hinge has a maximum extreme fiber strain of less than 0.0015 , even 

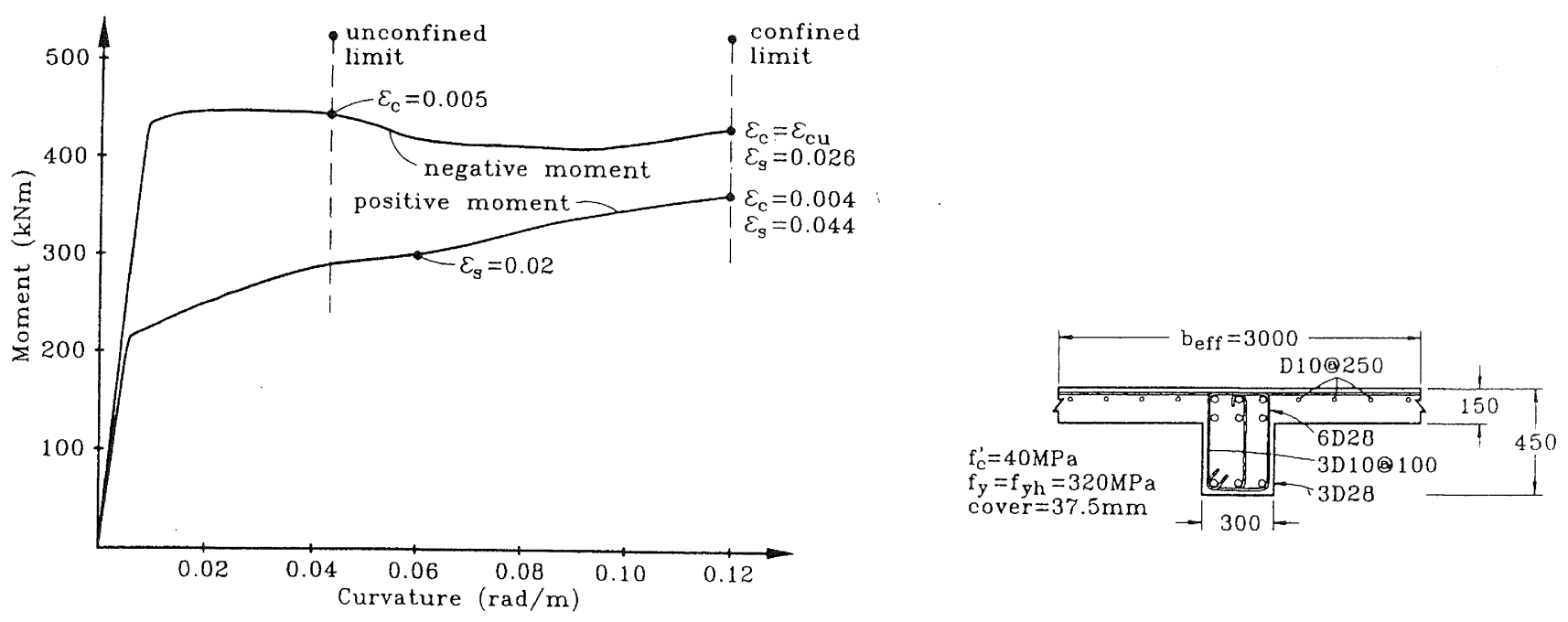

FIGURE 8 Moment-Curvature Relationships for Beam Example

assuming a reduced effective compression zone width of 1000 $\mathrm{mm}$. If the longitudinal reinforcement is properly confined by sets of 3 D10 bars at $100 \mathrm{~mm}$ centers, the ultimate negativemoment curvature increases from $0.046 \mathrm{radians} / \mathrm{m}$ to $0.12 \mathrm{radians} / \mathrm{m}$. At this curvature, spalling of cover concrete for the positive moment hinge is still not expected.

In fact, of course, the analysis for positive moment bending is simplistic, since under cyclic loading, the bottom reinforcement will be unable to yield the top reinforcement in compression, and thus a steel couple will develop, with slightly reduced moment capacity. Nevertheless, the conclusion that positive moment bending is not critical, remains.

For the example of Figure 8, an effective plastic hinge length of $L_{p}=0.08 \times 2775+0.022 \times 320 \times 28=401 \mathrm{~mm}$ is predicted from Equation (10). With a yield curvature of $\theta_{y}=0.009 \mathrm{radians} / \mathrm{m}$ (from moment-curvature analysis, or hand analyses), the plastic rotation capacity of the plastic hinge is found to be, for the unconfined case, $\theta_{p}=(0.046-0.009) \times$ $0.401=0.015$ radians.

\section{Column Hinge Flexural Capacity}

The procedure outlined above also applies, with minor changes, to hinges forming at column bases, or in column-sway inelastic mechanisms. However, the approximation for the volumetric ratio of transverse reinforcement in Equation (12) should be replaced by a first principles approach. In fact, it will often be found that columns in older reinforced concrete frames have only nominal transverse reinforcement, and thus must be considered to be unconfined. Together with reduced plastic hinge length as a consequence of reduced member height compared with beam length, and reduced ultimate curvature as a consequence of axial compression, column plastic rotation capacity will generally be less than values estimated for beams, and values less than $\theta_{p}=0.01$ will be common.

Since axial load critically affects the ultimate curvature, it is essential than seismic axial forces be included when estimating column plastic rotation. The critical column will be the one with highest axial compression. Moment-curvature analyses will show that, while yield curvature is not greatly affected by axial load level, particularly when yield curvature is expressed in terms of equivalent elasto-plastic response, ultimate curvature, and hence plastic rotation capacity is strongly dependent on axial load. This is illustrated in Figure 9, where an unconfined end column of a frame, with nominal axial load of $P=0.2 f_{c a}^{\prime} A_{g}$ is subjected to seismic axial force variations of $P_{E}= \pm 0.2 f_{c a}^{\prime} A_{g}$. The yield curvatures differ by less than $10 \%$ from the mean, while the ultimate curvatures at $P=0$ and $P=0.4 f_{c a}^{\prime} A_{g}$ are $61 \%$ and $263 \%$ of the value at $P=0.2 f_{c a}^{\prime} A_{g}$.

\section{Column Shear Strength}

Existing concrete frames of the 1930-1975 era will often be found to have only nominal transverse reinforcement, in the form of peripheral ties at spacing similar to the column dimensions. Shear strength assessment, using typical code equations for shear strength will frequently show these columns to be severely deficient, even when realistic, rather than nominal material strengths are used.

Code equations for shear strength are known to be excessively conservative, in many cases, and to show wide scatter when used to predict test results. It is thus recommended that column shear strength be assessed using equations that are more realistic than currently incorporated in codes, and which reflect the dependence of shear strength on flexural ductility. A recently developed model [16] which provides close agreement with experiments expresses the nominal shear strength of columns as the sum of components due to concrete contribution $\left(V_{c}\right)$, transverse reinforcement $\left(V_{s}\right)$ and axial load $V_{p}$. Thus

$$
V_{n}=V_{c}+V_{s}+V_{p}
$$

where

$$
\begin{gathered}
V_{c}=0.8 A_{\text {gross }} k \sqrt{f_{c a}^{\prime}} \\
V_{s}=\frac{A_{v} f_{y h} D^{\prime}}{s} \cdot\left(\cot 30^{\circ}\right) \quad \text { rectangular sections } \\
=\frac{\pi}{2} \frac{A_{s p} f_{y} D^{\prime}}{s}\left(\cot 30^{\circ}\right) \quad \text { circular sections }
\end{gathered}
$$



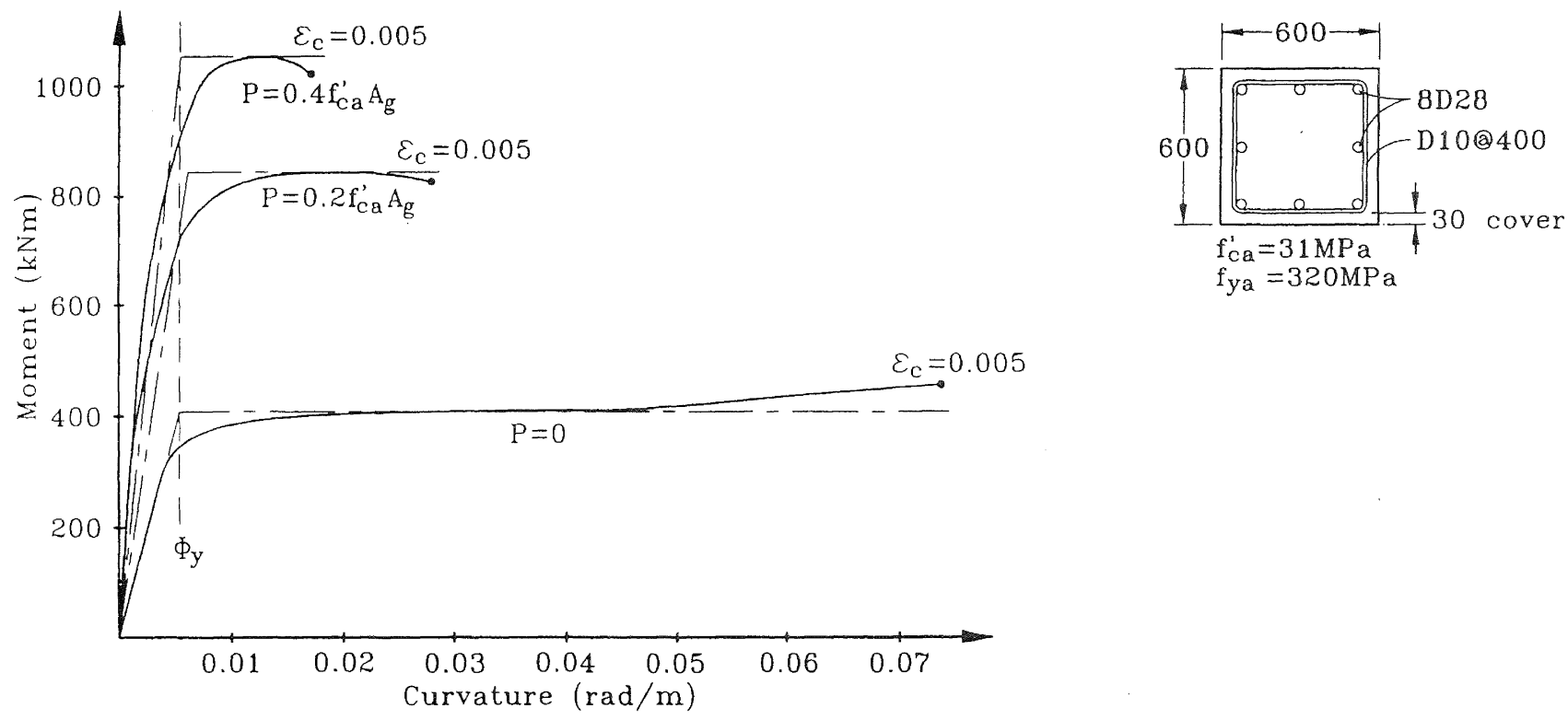

FIGURE 9 Moment Curvature Response of Unconfined Columns

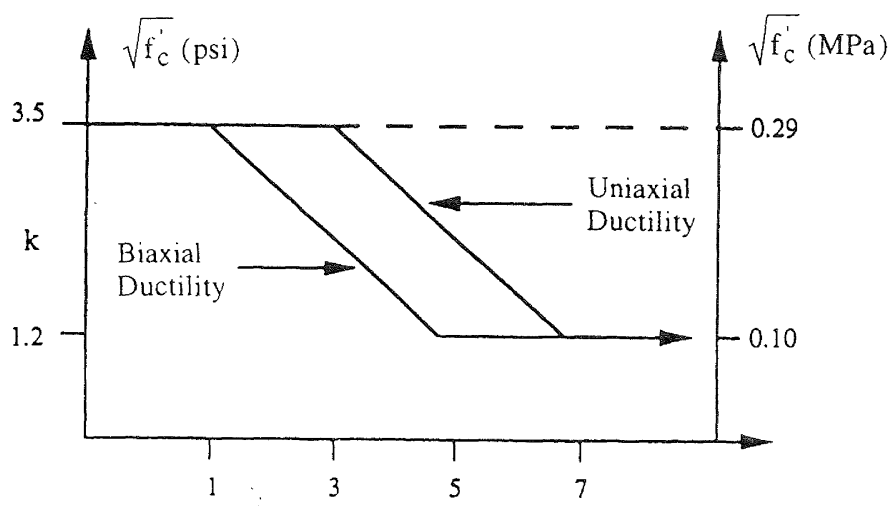

Section Curvature Ductility

(a) Degradation of Concrete Shear Strength with Ductility

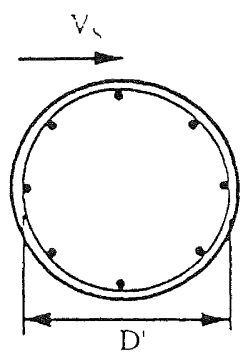

Circular Columns

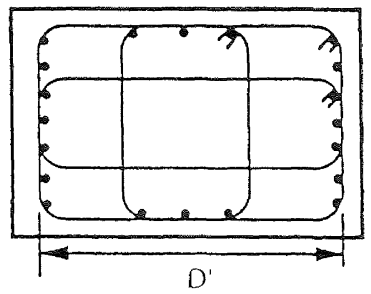

Rectangular Columns

(b) Definition of Terms for Shear Strength Analysis

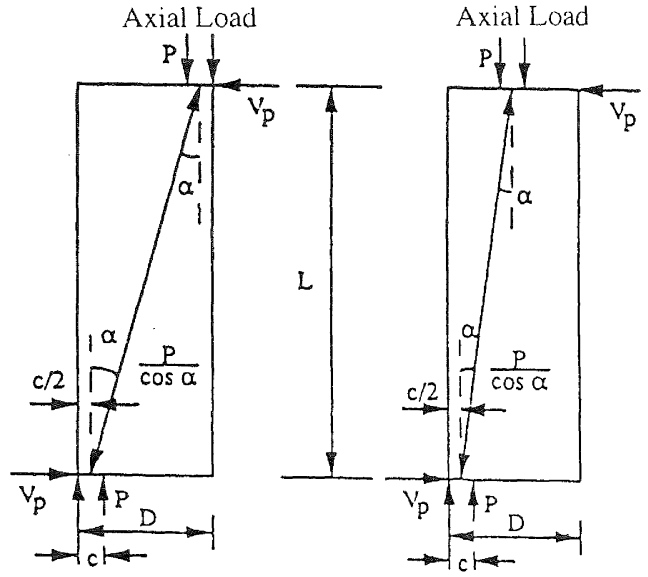

Reversed Bending

Single Bending

(c) Contribution of Axial Force to Column Shear Strength 
and

$$
V_{p}=P \tan \alpha
$$

Figure 10 describes the degradation of $k$ in Equation (14), with increasing curvature ductility $\mu_{\phi}=\phi / \phi_{y}$ the definition of $D^{\prime}$ in Equation (15) and the meaning of $\tan \alpha$ in Equation (16). A major difference from other models is that the contribution of axial force to shear strength is represented by the horizontal component of the axial force strut formed between top and bottom of the column. A full description of the model for shear strength is available in reference [16].

Two limit values, $V_{n i}$ and $V_{n d}$ corresponding to initial (maximum) and final (minimum) values for $k$ (from Figure 10a) result from Equation (13), and allow interpolation to find the member ductility at which shear failure can be expected, if $V_{n d}<V_{i f}$, where $V_{i f}$ is the shear force corresponding to column flexural strength. Thus the following equations apply.
Recent tests [16] indicate that the assumption of constant residual concrete shear strength, represented in Figure 10a by $k=0.1$ (MPa units) may be an oversimplification, and a further gradual reduction to $k=0.05$ ( $\mathrm{MPa}$ units) at $\mu_{\phi}=15$ seems appropriate.

\section{Beam Shear Strength}

The model in Figure 10a for shear strength degradation in plastic hinge regions has been rather extensively investigated for column sections. Although it is known that beam shear strength in plastic hinges reduces with ductility, an equivalent relationship has not been established for beams. In fact, there seems to be suprisingly little relevant data on which to base such a model. It would seem that there should not be much conceptual difference between a beam, and a column with zero axial load, and that, hence, Equations (14) and (15) should also apply directly to beams. However, columns generally have distributed longitudinal reinforcement, ensuring the existence of

Table 1 Ductility Capacity at Shear Failure (Equation 17)

\begin{tabular}{|c|c|c|c|}
\hline SHEAR FORCE & Uniaxial Ductility & Biaxial Ductility & EQUATION \\
\hline $\mathrm{V}_{\mathrm{if}} \geq \mathrm{V}_{\mathrm{ni}}$ & $\mu_{\phi \mathrm{s}} \leq 1$ & $\mu_{\phi \mathrm{s}} \leq 1$ & $17 \mathrm{a}$ \\
$\mathrm{V}_{\mathrm{if}} \leq \mathrm{V}_{\mathrm{nd}}$ & No shear failure, $\mu_{\phi}=\mu_{\phi \alpha}$ & No shear failure, $\mu_{\phi}=\mu_{\phi \alpha}$ & $17 \mathrm{~b}$ \\
$\mathrm{~V}_{\mathrm{nd}}<\mathrm{V}_{\mathrm{if}}<\mathrm{V}_{\mathrm{ni}}$ & $\mu_{\phi \mathrm{s}}=3+\frac{4\left(\mathrm{~V}_{\mathrm{ni}}-\mathrm{V}_{\mathrm{if}}\right)}{\left(\mathrm{V}_{\mathrm{ni}}-\mathrm{V}_{\mathrm{nd}}\right)}$ & $\mu_{\phi \mathrm{s}}=1+\frac{4\left(\mathrm{~V}_{\mathrm{ni}}-\mathrm{V}_{\mathrm{if}}\right)}{\left(\mathrm{V}_{\mathrm{ni}}-\mathrm{V}_{\mathrm{nd}}\right)}$ & $17 \mathrm{c}$ \\
\end{tabular}

In Equation (17), $\mu_{\phi s}$ and $\mu_{\phi \alpha}$ are the section curvature at shear failure and flexural failure, respectively. The outcome of Equation (17) thus depends on relative magnitudes of ideal flexural and shear strength, which will often be based on assumed material properties, in the absence of appropriate test data. Variations in material properties - particularly in the yield strength of the longitudinal reinforcement - can make significant differences to the outcome of Equation (17). This is particularly the case when the shear demand at ideal flexural strength, is only slightly lower than the ductile shear strength. In this case, a small increase in longitudinal yield strength can convert a predicted ductile response into a shear failure at significantly reduced ductility. As a consequence, and also to allow for scatter in the ratio between predicted and actual shear strength (see Figure 11), it is recommended that Equation (17) be used in conjunction with a shear strength reduction factor of $\phi_{s}=0.75$, when comparing shear strength and shear at nominal flexural strength of columns.

Comparison of observed shear strength with predictions of Equation (17) indicate rather close agreement for columns over a wide range of axial loads and ductility levels, as shown in Figure 11, for circular and rectangular sections [16]. In Figure 11, an earlier form of Equation (17), related to member displacement ductility, rather than section curvature ductility is used as the reference. For the data shown in Figure 11, the average relationship between displacement and curvature ductility can be approximated by

$$
\mu_{\phi}=1+2\left(\mu_{\Delta}-1\right)
$$

a flexural compression zone under cyclic inelastic response, even when $P=0$. With a beam section, the tension reinforcement area $A_{s}$ may be less than the compression reinforcement area, $A_{s}^{\prime}$, and under inelastic response no concrete compression will occur. Under these circumstances $V_{c}=0$ would seem appropriate at high ductilities. On the other hand, in building frames, the condition of $A_{s}^{\prime}>A_{s}$ is not likely to be critical for shear, since this represents the case of positive moment, when seismic and gravity shear forces act in opposition.

Until further test data become available, it is recommended that the shear strength of a negative-moment plastic hinge be assessed, using Equation (17), but with $k=0.2$ for $\mu_{\phi} \leq 3$ and $k=0.05$ for $\mu_{\phi} \geq 7$ in Equation (14).

\section{Beam-Column Joint Shear}

Current seismic design philosophy requires that considerable amounts of transverse reinforcement be placed in beam-column joints of reinforced concrete frames to assist in joint shear transfer $[11,14]$. However, the design methods, while being quite prescriptive, do not provide the necessary information to assess the strength and deformation capacity of sub-standard joints. Since older frame structures were almost always constructed without special joint reinforcement, this is a cause for concern

Recently, a considerable amount of research has been carried out in order to better quantify the performance of poorly designed joints. The vast body of data assembled by Japanese 


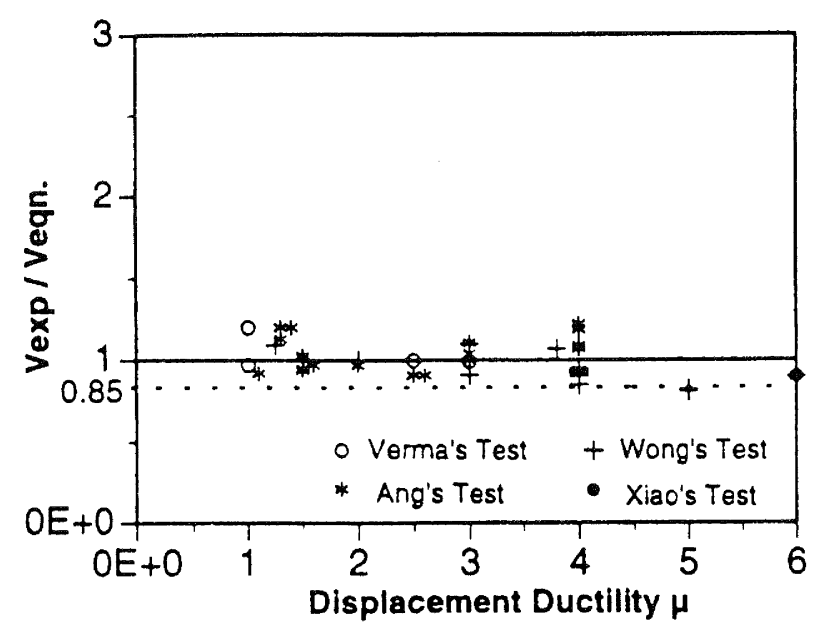

Circular Columns

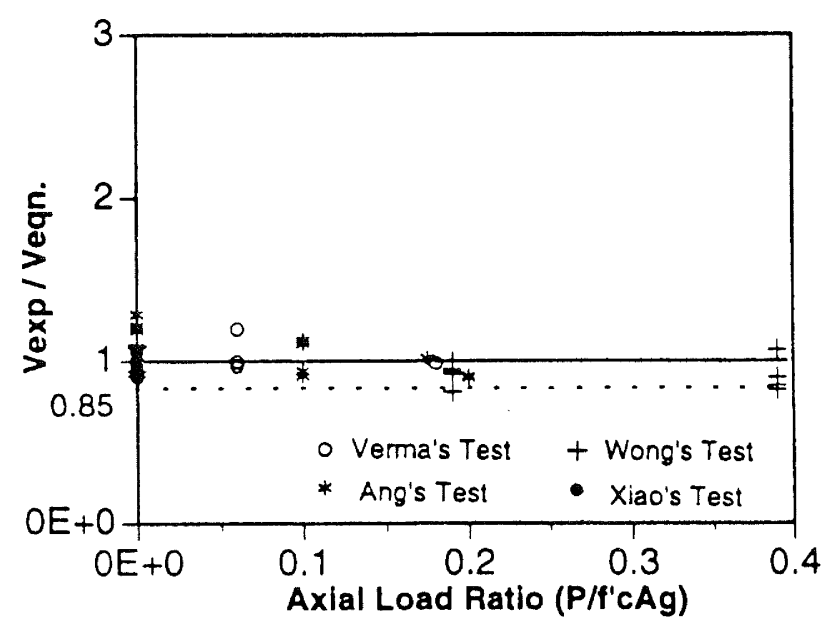

Circular Columns

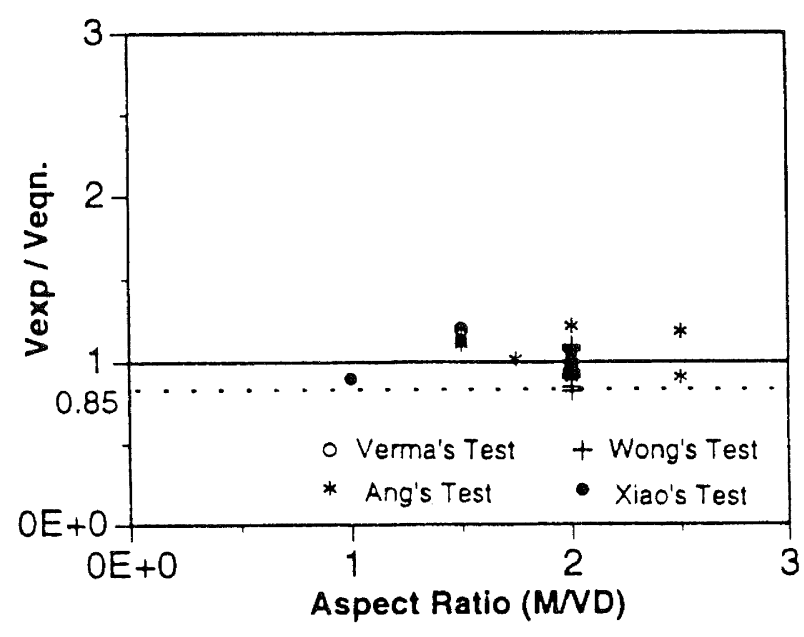

Circular Columns

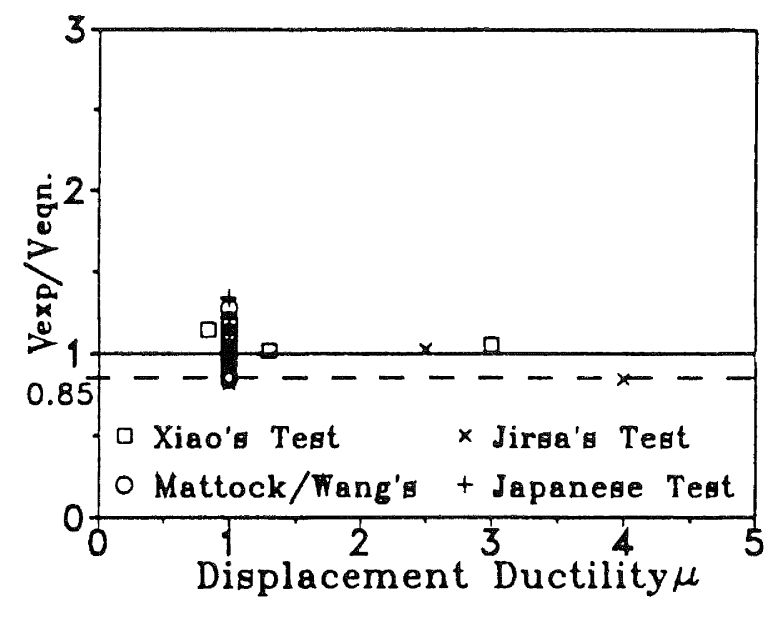

Rectangular Columns
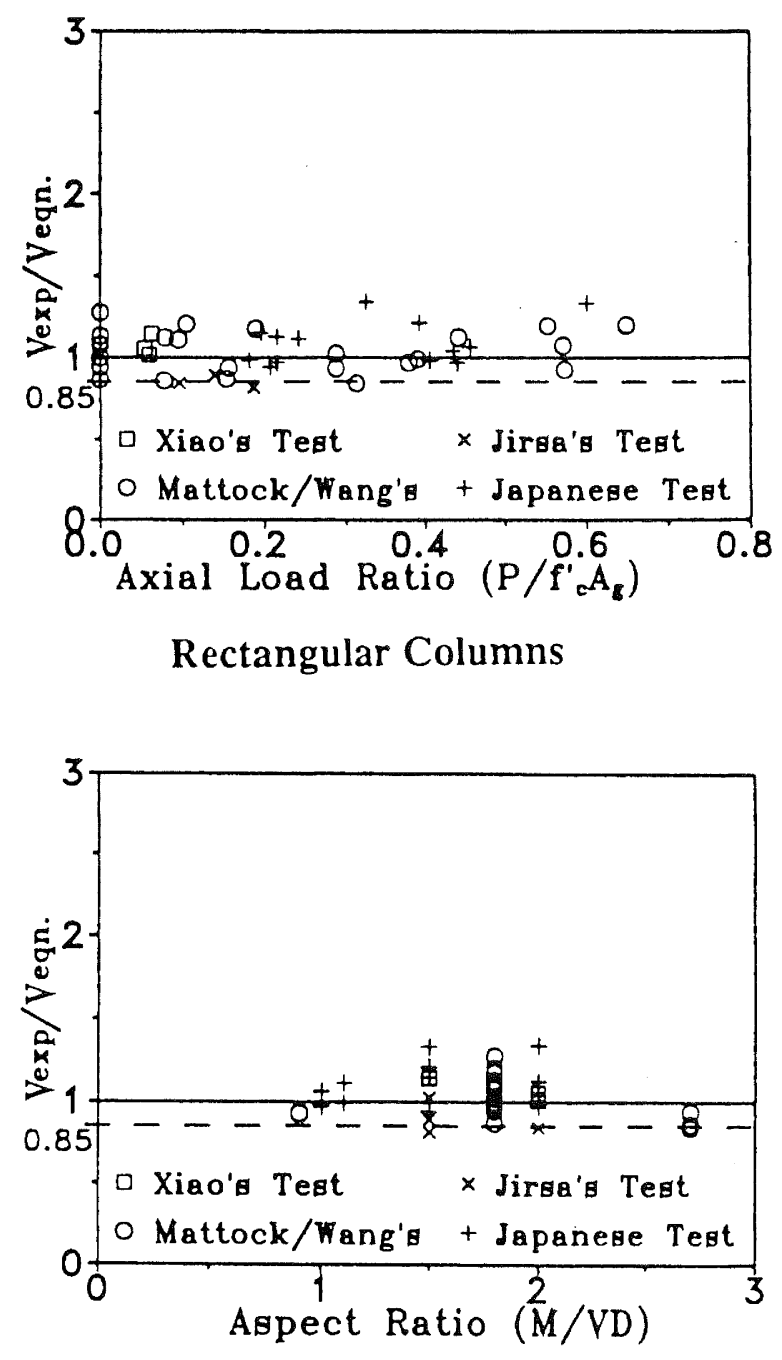

Rectangular Columns

FIGURE 11 Comparison of Measured Shear Strength with Predictions of Equation 17 


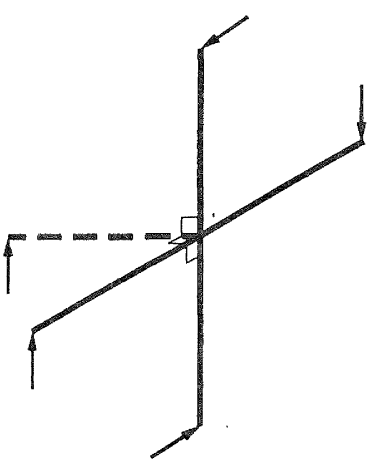

(a) One-way joint

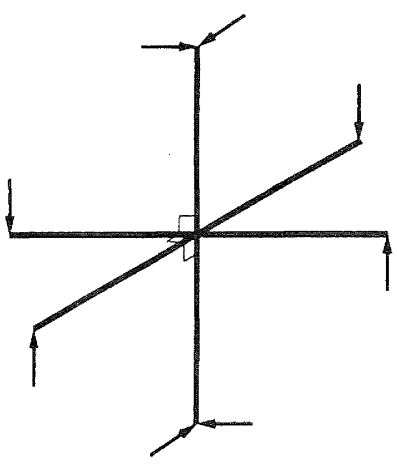

(b) Two-way joint

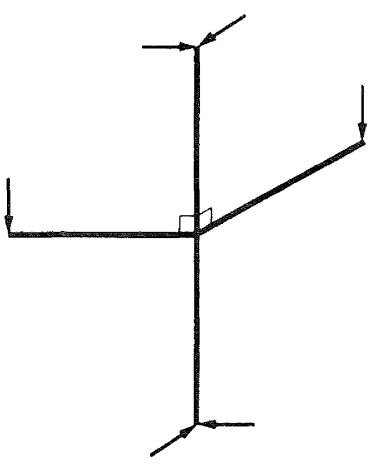

(c) Corner joint

FIGURE 12 Categories of Beam-Column Joints

researchers $[17,20]$ has been particularly useful in this regard. It is clear from this and other research carried out in New Zealand and the U.S.A., that there is a significant difference to be expected in the seismic performance of interior and exterior joints. Some observations from a review of this research, and tentative recommendations, are made below.

The distinction between "Interior" and "Exterior" joints, as discussed herein, is clarified by Figure 12. The joint in Figure 12a, part of an exterior frame is considered an interior joint for loading in the plane of the frame, but is an exterior joint in the orthogonal direction, suggested by the dashed line. 'True' interior joints, such as shown in Figure 12b, may be subjected to seismic response as interior joints in either, or both the two orthogonal directions. The corner joint of Figure 12c deserves special attention. There is reason to expect that corner joints might represent the critical conditions in building frames because of the biaxial input, typically difficult reinforcement detailing problems involved in anchoring two orthogonal sets of beam bars in the joint, and the influence of variable axial load. Despite this concern, there are almost no test data available for this type of joint.

\section{Interior Joints}

Review of the test data for interior joints indicates the following trends.

1. With lightly reinforced beams, or with columns with high axial force levels, joint cracking may not develop. The critical parameter here is the principal tension stress in the joint, rather than the shear stress level. Based on gross joint dimensions, a critical tension stress of

$$
p_{t}=-0.29 \sqrt{f_{c a}^{\prime}}
$$

seems appropriate, where

$$
p_{t}=\frac{f_{a}}{2}-\sqrt{\left(\frac{f_{a}}{2}\right)^{2}+v_{j}^{2}}
$$

and $f_{a}=P / A_{c o l}, v_{j}=V_{j h} / A_{c o l}$ are the average axial stress and shear stress in the joint core.

2. Beam-column joints with high shear stress levels tend to fail in shear regardless of the amount of transverse reinforcement. This is recognized in the U.S.A. by a limit of $v<1.7 \sqrt{f_{c a}^{\prime}} \mathrm{MPa}$ on joint shear stress. However, the reason for failure is the principal compression stress, and it is thus more logical to limit this directly, rather than through the shear stress, which does not recognize the influence of axial compression. Note that tests on joints with high axial loads and apparently adequate transverse reinforcement $[18,19]$ and with the comparatively low shear stress levels of $v_{c} \approx 1.0 \sqrt{f_{c a}^{\prime}}$ failed in shear. In both cases, the principal compression stress was about $0.5 f_{c a}^{\prime}$. Thus a tentative upper limit for shear stress would be related to the principal compression stress, by

$$
p_{c}=\frac{f_{a}}{2}+\sqrt{\left(\frac{f_{a}}{2}\right)^{2}+v_{j}^{2}} \leq 0.5 f_{c}^{\prime}
$$

Inverting Equation (20) yields

$$
v_{j} \leq p_{c} \sqrt{1-\left(\frac{f_{a}}{p_{c}}\right)}
$$

where, for one-way joints, $p_{c}=0.5 f_{c a}^{\prime}$, as above, and for two-way joints, $p_{c} \approx 0.45 f_{c a}$, to allow for effects of biaxial joint shear.

3. For beam-column joints with principal tension stress $p_{t}>-0.29 \sqrt{f_{c}^{\prime}}$ and principal compression stress $p_{c}<0.5 f_{c}^{\prime}$ (or $0.45 f_{c}^{\prime}$ for biaxial bending), failure may be due to joint shear, bond slip of rebar through the joint, or beam flexural ductility. In virtually all cases of interior test joints within this range, the flexural strength of the beams on both sides of the joint were developed before joint failure occurred, unless the columns were weaker than the beams.

For this category of interior joint, Japanese test results lead to the conclusions that:

- The role of transverse reinforcement seems different for cases where beam bar slip occurs, and where it is restrained. In the former case, hoop strains are largely independent of the amount of hoop reinforcement. In the latter case, hoop strains decrease as amount of hoop reinforcement increases.

- When beam bar bond failure occurs, the hysteresis loops become very pinched. Strength degradation typically starts at a drift angle of about $2 \%$. 


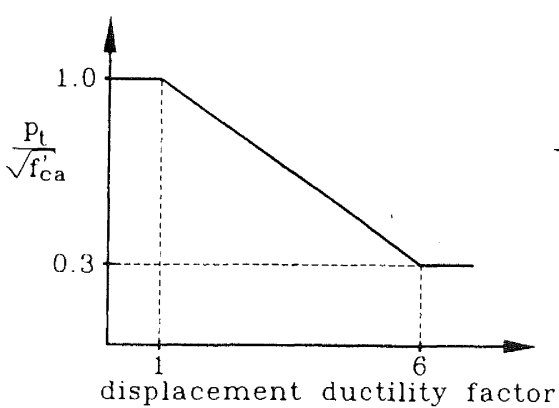

(a) Principal tension model of Hakuto, Park and Tanaka [20]

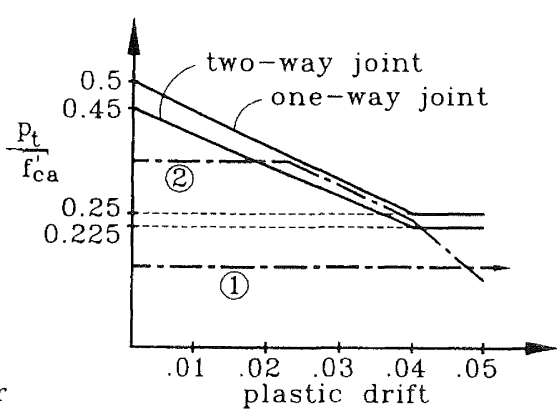

(b) Suggested principal compression model

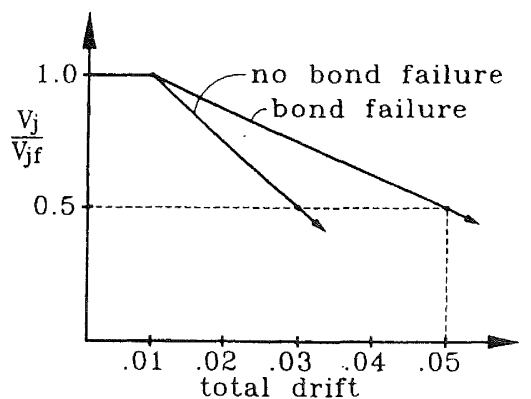

(c) Possible shear strength model

\section{FIGURE 13 Possible Failure Models for Interior Beam-Column Joints}

- When beam bar bond slip through the joint is inhibited (by provision of a larger joint width/beam bar diameter ratio), more force is transmitted to the joint by bond. Failure initiates in the joint at drift angles of about $2 \%$, if transverse reinforcement is insufficient to carry about $50 \%$ of the joint shear, and degrades more rapidly than when bond slip develops.

Definitive failure models are not yet available. Recently, however, Hakuto, Park and Tanaka [20] have suggested the principal tension model of Figure 13a. It is seen that the lower limit of this is similar to the principal tension stress suggested in relation to Equation (19). It seems that the upper limit, being based on tension rather than compression stress may result in anomolies when either high or low axial compressions are present. An alternative, but similar formulation, based on principal compression stress, and the observations listed above, is suggested in Figure 13b. In this, the principal compression stress ratio $p_{c} / f_{c a}^{\prime}$ is related to plastic drift, rather than joint displacement ductility. Line (1) indicates response of a joint with low principal compression stress, for which joint failure is not predicted. Line (2) represents a case with higher principal compression stress. For this case, strength commences to decline once the failure surface has been reached.

A third, and simpler formulation is suggested in Figure 13c, where, provided $p_{c}<0.5 f_{c a}^{\prime}$ (or $0.45 f_{c a}^{\prime}$ for two-way joints), the joint shear strength ratio $V_{j} / V_{\text {if }}$ is assumed to start degrading at $1 \%$ drift, regardless of the actual shear stress or principal stress level. In this formulation, $V_{\text {if }}$ is the joint shear corresponding to beam flexural strength. This model has the merit of capturing the essentials of the failure mechanism noted by others for under-reinforced joints, but it should be stressed that neither the model of Figure 13c nor that of Figure 13b have been adequately tested to date. It is felt, however, that the model of Figure 13c is likely to prove of adequate conservatism for assessment.

\section{Exterior and Corner Joints}

As with interior joints, a principal tension stress of about $0.29 \sqrt{f_{c}^{\prime}} \mathrm{MPa}$ appears to be a lower limit for joint cracking. When beam reinforcement is anchored by bending away from the joint (see Figure 14a), diagonal struts in the joint cannot be

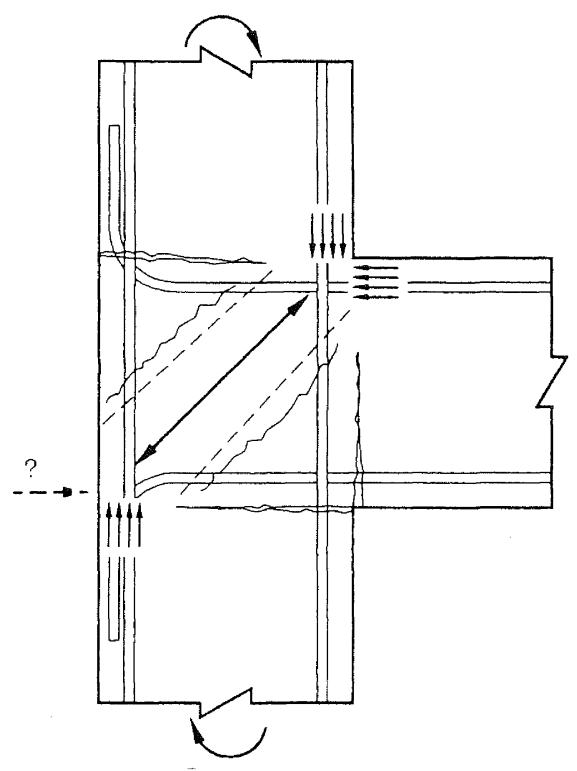

(a) Beam bars bent away from joint

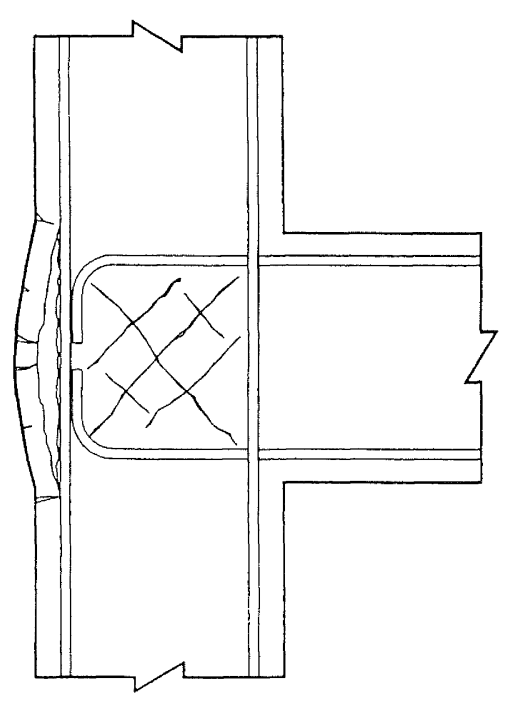

(b) Beam bars bent in: cover cracking at back of joint

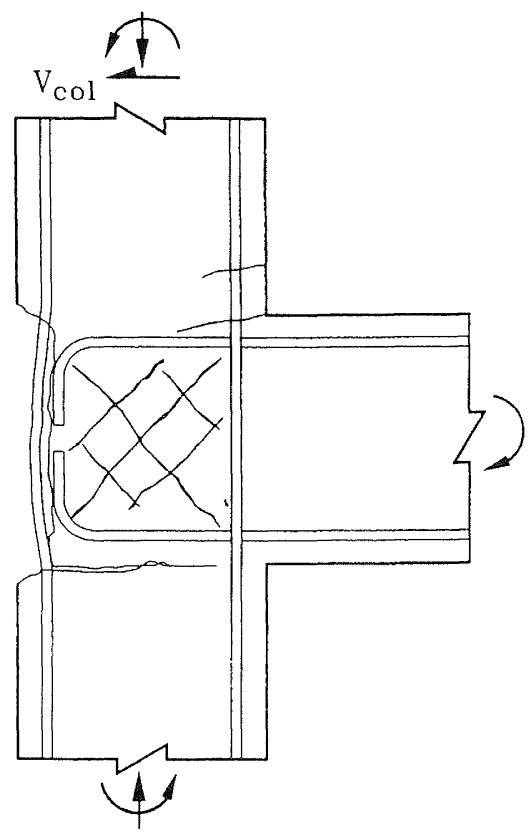

(c) Loss of joint integrity

FIGURE 14 Breakdown of Unreinforced Exterior Joints 
stabilized, and joint failure occurs at an early stage. The situation when beam reinforcement is bent down into the joint is illustrated in Figs. 14b and 14c. Joint cracking will first develop under positive beam moments, since axial force on the column is reduced for this direction of response. In a multistory building, the axial force variations in exterior, and in particular, in corner columns can be very high, and as a consequence, cracking under negative moment will be delayed, and may not occur at all.

When cracking occurs, the joint tends to dilate horizontally. This places the cover concrete at the back of the joint in curvature and vertical cracking occurs on the weak plane at the line of column reinforcement, particularly if beam reinforcement hooks lie in the same plane. This is illustrated in Figure 14b. The cover concrete is likely to spall off under the increase compression load corresponding to beam negative moment. In unreinforced joints this severely degrades the anchorage of the beam bar hooks, which is needed to equilibrate the diagonal strut in the joint. The combined action of resistance to this diagonal strut and the pulling force from the beam reinforcement tension force tends to open the hooks, as shown in Figure 14c, further degrading joint performance. Joint degradation is then comparatively rapid.

Comparatively small amounts of transverse joint reinforcement greatly improve the behavior. Joint dilation is reduced, as is the tendency for cover spalling at the back of the joint. This still occurs, but at a later stage of response. Straightening of the beam bar hooks is restrained, maintaining integrity of the diagonal compression strut.

It is evident that failure of exterior joints is primarily related to principal tension stress. The following tentative recommendations are based on tests of unreinforced exterior and corner joints.

1. For beam bars bent away from the joint, joint failure can be considered to initiate at a principal tension stress of $0.29 \sqrt{f_{c a}^{\prime}} \mathrm{MPa}$.

2. For beam bars bent down across the back of the joint, higher principal tension stresses are possible. The test data support principal tension stresses of $0.42 \sqrt{f_{c a}^{\prime}} \mathrm{MPa}$ and $0.58 \sqrt{f_{c a}^{\prime}} \mathrm{MPa}$ for exterior joints, and corner joints under biaxial response, respectively. Note that under diagonal response of corner joints the joint shear force is formed from vectorial addition of the orthogonal shears.

3. Joint degradation after formation of cracking is governed by gradual reduction of the effective joint principal tension stress, in accordance with the relationship suggested in Figure 15 .

The information provided above enables an estimate to be made of the plastic story drift that could occur when a joint-failure mechanism develops. Note that the degradation will often be found to be quite gradual in terms of story shear strength reduction. However, if joint failure can occur at two adjacent levels of a building, a soft story sway mechanism can develop, and the structural ductility capacity $\mu_{s}$ will be found to be low. Also, energy dissipation with a joint failure mechanism is less than for a beam or column sway mechanism. It is recommended that a flat $10 \%$ effective viscous damping be used in the displacement-based assessment procedure outlined above.

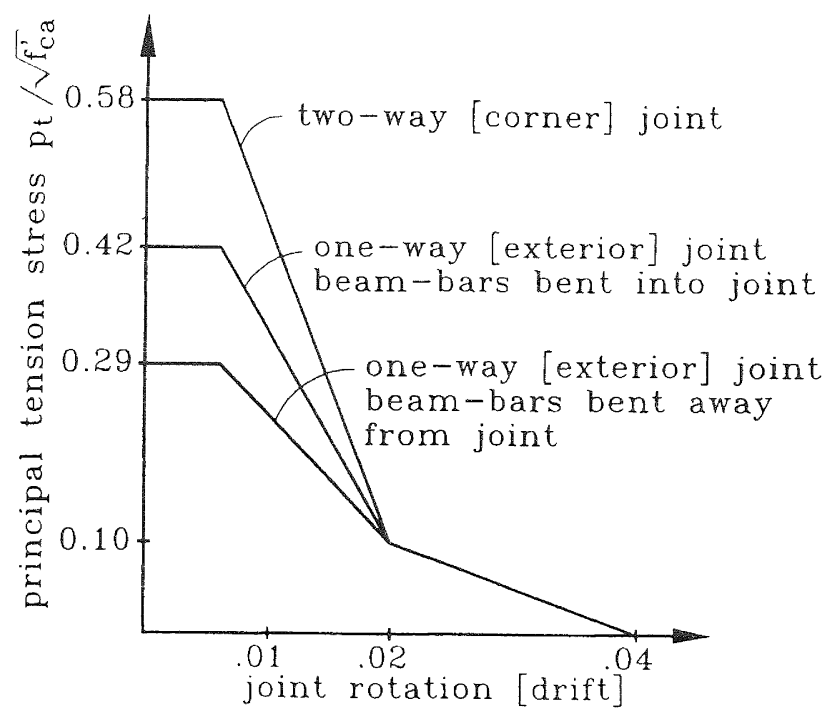

FIGURE 15 Suggested Strength Degradation Model for Exterior and Corner Joints

A strength reduction factor of $\phi_{s}=0.75$, as for shear, should be used in conjunction with calculated joint shear strength, to account for potential overstrength of beam plastic hinges.

\section{STRUCTURAL WALL BUILDINGS}

Many of the principles outlined above are directly applicable to buildings where the principal form of lateral resistance is structural walls. Traditionally, buildings with structural walls in both orthogonal directions have performed well in earthquakes (e.g., Chile, 1985 [21]) even when the walls have not been designed to capacity principles. However, when walls are provided in only one direction, and the frames in the orthogonal direction develop column-sway mechanisms, the excessive lateral drift in the walls can cause instability and premature collapse, as occurred in many buildings in the 1995 Kobe earthquake [22].

Some of the aspects of assessment of structural walls are illustrated in Figure 16, which shows a simple cantilever wall, linked to other structural elements by flexible floor slabs. Flexural reinforcement (Figure 16a) reduces with height, reflecting the anticipated decreased flexural demand. Figure $16 \mathrm{~b}$ compares various moment profiles up the wall height with the computed moment capacity. Profile (1) assumes a base moment equal to calculated flexural strength, and an inverted triangle distribution of lateral force. The effects of higher modes would be included by using profile (2) for design, where moments decrease linearly with height to zero $[11,14]$. To account for effects of diagonal cracking, a tension shift is normally applied to the moment diagram, displacing profile (2) vertically by an amount equal to the wall length $\ell_{w^{\prime}}$.

For assessment, this approach, which is desirably conservative for design, can be somewhat modified. First, the tension shift can be reduced to $0.5 \ell_{w}$, as shown in Figure 16b, where profiles (3) and (4) show tension shift applied to profiles (1) and (2) respectively. Second, if the wall nominal shear stress $V / A_{w^{\prime}}<0.2 \sqrt{f_{c a}^{\prime}} \mathrm{MPa}$, diagonal cracking is unlikely to develop and tension shift is inappropriate. This critical shear stress level 


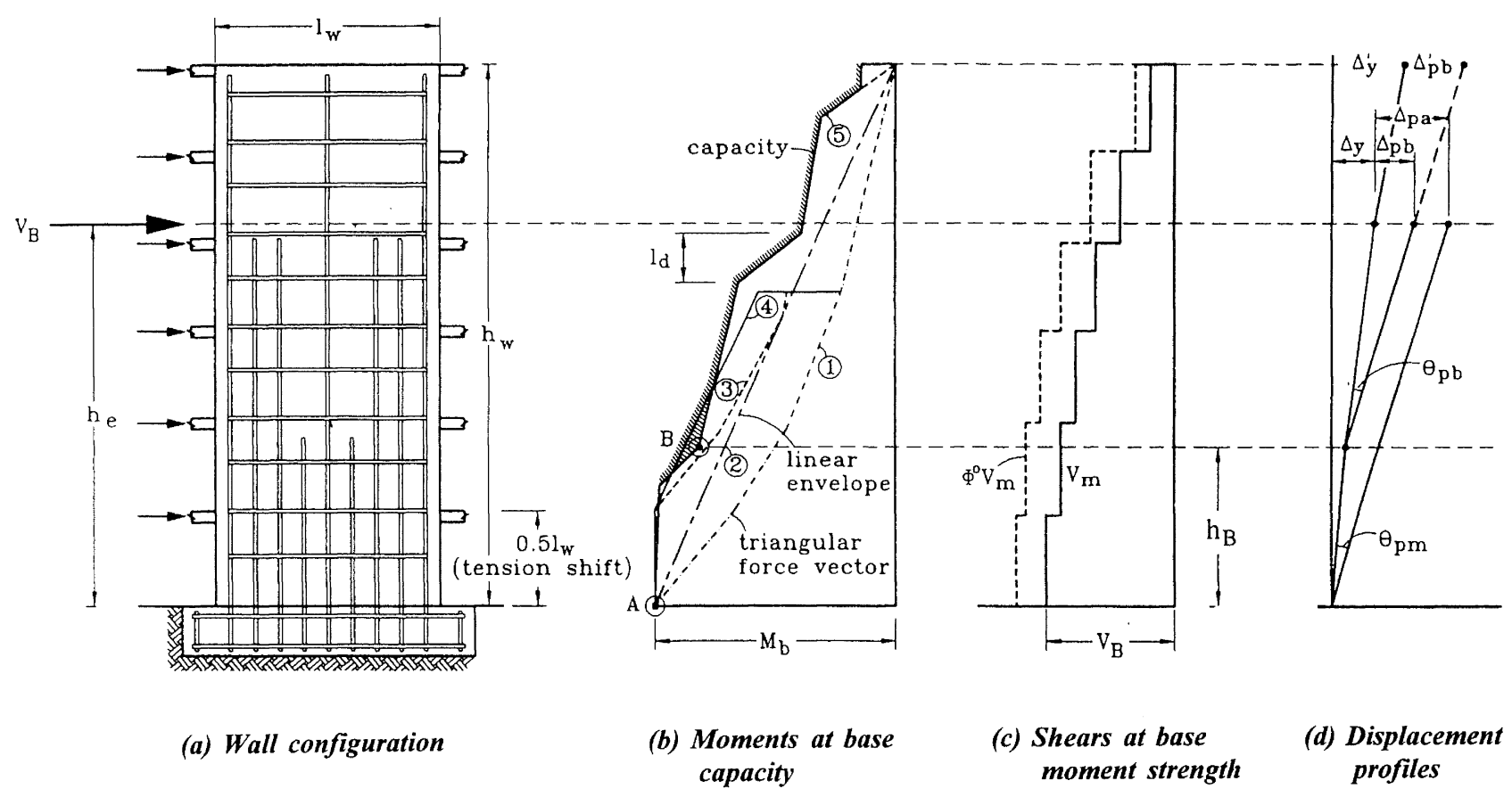

FIGURE 16 Assessment of a Cantilever Wall

is achieved slightly above wall midheight. Above this level, profiles (3) and (4) revert to profiles (1) and (2).

The calculated moment capacity is represented by profile (5), which includes effects of gradual moment increase over the development length $\ell_{d}$ adjacent to rebar termination. A cracking moment capacity $M_{c r}$ exceeds ultimate strength at the top of the wall.

Comparison of profiles (4) and (5) indicate that plastic hinging could develop at the wall base (point A), or just below the second floor, at point $\mathrm{B}$. However, it is noted that the capacity at $B$ exceeds profile (3), and thus hinging is not predicted under the normal triangular force vector, but only when higher modes are considered. It is unlikely that significant inelastic displacement demand will occur in this condition. Consequently, for assessment, it is decided to base inelastic response on a base hinge. If the capacity at B (or elsewhere) was less than that of profile (3), a different conclusion would be reached.

Assessment of shear strength is included in Figure 16c. Here, $V_{m}$ is the shear force distribution corresponding to the triangular force vector, and base moment capacity $M_{b}$. That is,

$$
V_{B}=M_{b} / h_{e}
$$

In capacity design for new buildings, the design shear force distribution would be taken as

$$
V=\omega \phi_{0} V_{m}
$$

where $\phi_{0}$ represents potential flexural overstrength due to high material strengths, and strain hardening, and $\omega$ represents dynamic shear amplification due to higher mode effects [11, 14]. It will be noted that assuming maximum values for $\omega$ and $\phi_{0}$ simultaneously is conservative since maximum curvature ductility (and hence maximum $\phi_{0}$ ) cannot occur simultaneously with maximum higher mode response. Also, dynamic analyses tend to indicate that the duration of dynamically amplified shears is typically extremely short. It thus seems unlikely that sufficient energy could be fed into the wall to sustain the displacements necessary for a full shear failure. Consequently, it is suggested that the shear strength of the wall be checked only against $V=\phi_{0} V_{m}$. To simplify the assessment, it is suggested that this be effected by use of an artificially low shear strength reduction factor $\phi_{s}=0.75$, as was suggested for frame members, and shear demand corresponding to nominal flexural strength.

Wall shear strength may be assessed using Equations. (13) through (17), since the difference between walls and columns is primarily one of semantics. Agreement of predicted and measured shear strength, using these equations appears reasonable, though the testing has not yet been as exhaustive as it should be.

Calculation of plastic displacement capacity also follows the methods suggested for frame members. For a hinge forming at the wall base, the plastic hinge length is given by Equation (10), substituting $L=h_{e}$, and the plastic rotation by Equation (9). An ultimate compression strain for unconfined concrete may again be conservatively taken as $\epsilon_{c}=0.005$, and the effect of confinement based on the volumetric ratio of confinement at the wall ends, using Equation (11). In the event that a wall hinge is predicted at point $B$, Figure $16 \mathrm{~b}$, the plastic displacement at the center of seismic force will be

$$
\Delta p_{B}=\theta p_{B}\left(h_{e}-h_{B}\right)
$$

instead of

$$
\Delta p_{A}=\theta p_{A} h_{e}
$$

However, if plastic hinging at $\mathrm{B}$ is a consequence of higher mode effects, as previously discussed, based on a linear moment-demand envelope, it is probably unrealistically 
conservative to carry out the displacement calculation at the effective height $h_{e}$, which is based on the assumption of a triangular force vector. Perhaps calculating $\Delta_{y}^{\prime}$ and $\Delta p_{B}^{\prime}$ at the wall top would be more appropriate.

The above discussion is simplistic, but illustrates most of the aspects that need to be considered in a wall assessment. For multiple cantilever walls, the force-deflection response of all walls can be added to provide the total response from which the structural effective stiffness and damping, in accordance with Figure 2, are estimated. The assessment of coupled walls requires procedures which are intermediate between those for walls and frames, though no conceptual difficulties arise. In this context, it should be mentioned that the coupling effects of reinforced concrete slabs can be considerable, in increasing elastic stiffness, and lateral strength of structural wall buildings.

Finally, the capacity of the floor diaphragms, and their connections to the structural walls must be checked to ensure they can distribute the inertia forces adequately in accordance with assumptions made in the assessment.

\section{CONCLUSIONS}

An attempt has been made to describe an assessment procedure for reinforced concrete buildings, based on displacement considerations using a substitute structure approach representing stiffness and effective damping at maximum displacement capacity, rather than initial stiffness values and force-based assessment. The procedure is conceptually straightforward, and eliminates many of the concerns that arise from trying to assess buildings in comparison with code lateral force levels.

Some of the material presented is tentative, and requires further development. In particular, the information on strength and deformation capacity of unreinforced beam column joints must be considered preliminary, at best. Current work in progress by Restrepo ${ }^{1}$, shortly to be reported, shows considerable promise in this area. In the meantime, the information presented is felt to be reasonably conservative, but much more liberal than in the earlier approach [7].

It remains to be asked what should be the recommendation when, as will often be the case, the assessed risk of failure exceeds that considered acceptable for new buildings. To some extent this is a public policy decision, rather than a question to be answered by engineers. It may be felt appropriate to permit a specified higher risk for older structures. This is only tenable on the basis that the public must accept higher risk over the remaining life of the structure because the economic consequences of upgrading all old buildings is not cost effective. It has been suggested that the increased risk of failure for an older building be accommodated by defining a reduced 'specified remaining life' for the structure. This is not rational. It implies that the risk of failure of a building, over its life is more important than the annual risk of failure, which is the true risk to the public. Further, after the 'specified remaining life' of the structure expired, without the advent of a damaging earthquake, it would seem theoretically reasonable to again assess the building, establishing the same annual risk of failure, and thus extending the life again. This makes a mockery of the risk process.

1 Personal communication - José Restrepo, University of Canterbury, New Zealand.

\section{ACKNOWLEDGMENTS}

Much of the basis for this paper has resulted from research funded by the California Department of Transportation (Caltrans), at the University of California, San Diego. The support of Caltrans, and that of the New Zealand Earthquake Commission, is gratefully acknowledged.

\section{REFERENCES}

1. City of Long Beach - Ordinance No. C.5276 Long Beach Municipal Code.

2. New Zealand Government 1979. Local Government Act, 1979, Section 624.

3. Japanese Building Disaster Prevention Association, 1977. National Standard for Seismic Evaluation of Existing Reinforced Concrete Buildings, Japan, 131 p.

4. Applied Technology Council 1988. Rapid Visual Screening of Building for Potential Seismic Hazards (ATC21). Redwood City, 189 p.

5. Applied Technology Council 1989. Handbook for Seismic Evaluation of Existing Buildings (Preliminary) - (ATC22). Redwood City, 169 p.

6. Applied Technology Council. Evaluating the Seismic Resistance of Existing Buildings (ATC14). Redwood City, $370 \mathrm{p}$.

7. Priestley, M.J. Nigel and G. Michele Calvi, 1991. Towards a Capacity - Design Assessment Procedure for Reinforced Concrete Frames, Earthquake Spectra, $7(3): 413-437$.

8. Priestley, M.J.N., and Seible, F., 1994. Seismic Assessment of Existing Bridges, Proceedings of the Second International Workshop on the Seismic Design of Bridges, Queenstown, New Zealand, 2:46-70.

9. Priestley, M.J. Nigel, Frieder Seible and Michele Calvi, 1996. Seismic Design and Retrofit of Bridges, John Wiley and Sons, Inc., New York.

10. Shibata A., and Sozen, M., 1976. Substitute Structure Method for Seismic Design in Reinforced Concrete, Journal Structural Division, ASCE, 102(1).

11. Paulay, T., and Priestley, M.J.N., 1992. Seismic Design of Reinforced Concrete and Masonry Buildings, John Wiley \& Sons, Inc., New York, 714 p.

12. SC-PUSH3D Users Manual. SC-Solutions, Redwood City, CA.

13. Carr, A.J., 1995. Ruaumoko Users Manual, University of Canterbury, New Zealand.

14. NZS 3101:1995. Design of Concrete Structures, Vols. I and 2, Standards Association of New Zealand, Wellington. 
15. Mander, J.B., M.J.N. Priestley and R. Park, 1988 Theoretical Stress-Strain Model for Confined Concrete, ASCE Journal of Structural Engineering, 114(8): 1827-1849.

16. Priestley, M.J. Nigel, Ravindra Verma and Yan Xiao, 1994. Seismic Shear Strength of Reinforced Concrete Columns, ASCE Journal of Structural Engineering, 120(8): 2310-2329.

17. Kurase, Y., 1987. Recent Studies on Reinforced Concrete Beam-Column Joints in Japan, PMFSEL Report No. 87-8, University of Texas at Austin, $164 \mathrm{p}$.

18. Pessiki, S.P., Conley, C.H., Gergely, P., and White, R.N., 1990. Seismic Behavior of Lightly Reinforced Concrete Column and Beam-Column Joint Details, NCEER Technical Report No. 90-0014, State University of New York at Buffalo.

19. Beckingsale, C.W., 1980. Post-Elastic Behaviour of Reinforced Concrete Beam-Column Joints, Research Report No. 80-20, Department of Civil Engineering, University of Canterbury, $398 \mathrm{p}$.

20. Hakuto, S., Park, R., and Tanaka, H., 1995. Retrofitting of Reinforced Concrete Moment Resisting Frames, Research Report 95-4, Department of Civil Engineering, University of Canterbury, Christchurch, New Zealand.

21 Wyllie, L.A., et al., 1986. The Chile Earthquake of March 3, 1985, Earthquake Spectra, 2(2), 513 p.

22. Priestley, M.J.N., F. Seible and G. MacRae, 1995. The Kobe Earthquake of January 17, 1995 - Initial Impressions from a Quick Reconnaissance, Structural Systems Research Project, Report No. SSRP-95/03, University of California, San Diego, $71 \mathrm{p}$. 